\title{
Characterization of Antineovascularization Activity and Ocular Pharmacokinetics of Phosphoinositide 3-Kinase/Mammalian Target of Rapamycin Inhibitor GNE-947
}

\author{
Xingrong Liu, Xiaorong Liang, Jenninfer LeCouter, Savita Ubhayakar, Jacob Chen, Jay Cheng, \\ Tom Lee, Joe Lubach, Jim Nonomiya, Sheerin Shahidi-Latham, Cristine Quiason, Eric Solon, \\ Matthew Wright, Cornelis E.C.A. Hop, and Timothy P. Heffron
}

Genentech, Inc., South San Francisco, California (X.Liu., X.Lia., J.L., S.U., J.Chen, J.Cheng, T.L., J.L., J.N., S.S.-L., C.Q., E.S., M.W., C.E.C.A.H., T.P.H.) and QPS, Delaware Technology Park, Newark, Delaware (E.S.)

Received October 18, 2019; accepted January 19, 2020

\begin{abstract}
The objectives of the present study were to characterize GNE-947 for its phosphoinositide 3-kinase (PI3K) and mammalian target of rapamycin (mTOR) inhibitory activities, in vitro anti-cell migration activity in human umbilical vein endothelial cells (HUVECs), in vivo antineovascularization activity in laser-induced rat choroidal neovascular (CNV) eyes, pharmacokinetics in rabbit plasma and eyes, and ocular distribution using matrix-assisted laser desorption/ ionization imaging mass spectrometry (MALDI-IMS) and autoradioluminography. Its PI3K and mTOR $K_{\mathrm{i}}$ were 0.0005 and $0.045 \mu \mathrm{M}$, respectively, and its HUVEC IC I0 $_{50}$ was $0.093 \mu \mathrm{M}$. GNE-947 prevented neovascularization in the rat CNV model at 50 or $100 \mu \mathrm{g}$ per eye with repeat dosing. After a single intravenous injection at 2.5 and $500 \mu \mathrm{g} / \mathrm{kg}$ in rabbits, its plasma terminal half-lives $\left(t_{1 / 2}\right)$ were 9.11 and 9.59 hours, respectively. After a single intravitreal injection of a solution at $2.5 \mu \mathrm{g}$ per eye in rabbits, its apparent $t_{1 / 2}$ values were 14.4, 16.3, and 23.2 hours in the plasma, vitreous humor, and aqueous humor, respectively. After a single intravitreal injection of a suspension at $33.5,100,200 \mu$ g per eye in rabbits, the $t_{1 / 2}$ were 29 , 74 , and 219 days in the plasma and 46, 143, and 191 days in the eyes,
\end{abstract}

respectively. MALDI-IMS and autoradioluminography images show that GNE-947 did not homogenously distribute in the vitreous humor and aggregated at the injection sites after injection of the suspension, which was responsible for the long $t_{1 / 2}$ of the suspension because of the slow dissolution process. This hypothesis was supported by pharmacokinetic modeling analyses. In conclusion, the PI3K/mTOR inhibitor GNE-947 prevented neovascularization in a rat $C N V$ model, with $t_{1 / 2}$ up to approximately 6 months after a single intravitreal injection of the suspension in rabbit eyes.

\section{SIGNIFICANCE STATEMENT}

GNE-947 is a potent phosphoinositide 3-kinase/mammalian target of rapamycin inhibitor and exhibits anti-choroidal neovascular activity in rat eyes. The duration of GNE-947 in the rabbit eyes after intravitreal injection in a solution is short, with a half-life $\left(t_{1 / 2}\right)$ of less than a day. However, the duration after intravitreal dose of a suspension is long, with $t_{1 / 2}$ up to 6 months due to low solubility and slow dissolution. These results indicate that intravitreal injection of a suspension for low-solubility drugs can be used to achieve long-term drug exposure.

\section{Introduction}

Vascular endothelial growth factor (VEGF) is a potent, diffusible, endothelial-specific mitogen and a blood vessel permeability factor induced during the progression of intraocular vascular pathologies. It is a clinically validated antiangiogenic and vascular permeability target in neovascular (wet) age-related macular degeneration (NV AMD) (Ferrara et al., 2006; Miller et al., 2013). As such, VEGF-neutralizing agents, including an antibody-based therapy, such as ranibizumab (rhuFAb VEGF, Lucentis; Genentech, Inc., South San Francisco, CA), and a VEGF decoy receptor and antibody fragment crystallizable-chimeric protein, aflibercept (VEGF-TRAPR1R2, VIEW1/2, Eylea; Regeneron,

https://doi.org/10.1124/dmd.119.089763.

S This article has supplemental material available at dmd.aspetjournals.org.
Tarrytown, NY), are now used as standards in the clinical management of NV AMD and other ocular diseases, including central retinal vein occlusion. Despite the clinical successes of currently available antiVEGF therapies, there is still a significant unmet medical need in the treatment of NV AMD with respect to both maximizing the magnitude of visual gains and the durability of effects. Approximately $30 \%$ of patients had an improved best-corrected visual acuity of equal to or greater than 15 letters in pivotal clinical trials with ranibizumab (Chang et al., 2007; Bressler et al., 2009; Busbee et al., 2013) and aflibercept (Heier et al., 2012). The majority of patients in these studies did not achieve a 15-letter improvement in visual acuity, and approximately $29 \%$ of patients continued to lose vision, suggesting that there are additional signaling pathways and/or mechanisms promoting pathologic neovessel growth, leakage, and loss of retinal function in patients with NV AMD.

ABBREVIATIONS: AUC, area under the curve; CNV, choroidal neovascular; GRP-1, general receptor for phosphoinositides, isofrom 1; HUVEC, human umbilical vein endothelial cell; IMS, imaging mass spectrometry; LC-MS/MS, Liquid Chromatography with tandem mass spectrometry; MALDI, matrix-assisted laser desorption/ionization; MRM, multiple reaction monitoring; mTOR, mammalian target of rapamycin; NV AMD, neovascular age-related macular degeneration; PI3K, phosphoinositide 3-kinase; PIP3, 3,4,5-inositoltriphosphate; PK, pharmacokinetics; $t_{1 / 2}$, halflife; VEGF, vascular endothelial growth factor; VEGFR-2, VEGF receptor 2. 
VEGF receptor 2 (VEGFR-2) is the tyrosine kinase receptor that signals VEGF-mediated endothelial cell growth, survival, vessel morphogenesis, and permeability [reviewed in Ferrara et al. (2003)]. VEGFR-2 signals primarily through the phosphatidyl inositol 3-kinase pathway (Gerber et al., 1998; Ferrara 1999). Specifically, the class I phosphoinositide 3-kinase (PI3K) kinases and mammalian target of rapamycin (mTOR) kinase (a member of the phosphatidyl inositol-like kinase family) have been demonstrated to be required for angiogenesis and vascular integrity in vivo (Hamada et al., 2005; Graupera et al., 2008; Schnell et al., 2008; Yuan et al., 2008; Sampath et al., 2013). GNE-947 is an inhibitor of the class I PI3K kinases and the downstream mTOR kinase (Figs. 1 and 2). This dual targeting permits a more potent VEGFR-2 pathway inhibition than more-selective compounds and alleviates the feedback activation loop downstream of selective mTOR inhibitors (O'Reilly et al., 2006; Wallin et al., 2012).

In addition to VEGFR, the PI3K/mTOR pathway is used by many receptor systems implicated in NV AMD, including platelet-derived growth factor B and the bioactive lipid sphingosine-1-phosphate, suggesting that inhibiting PI3K/mTOR in the eye may have a broader therapeutic utility than only targeting VEGF (Jo et al., 2006; Caballero et al., 2009). Thus, GNE-947 may offer a single therapy to inhibit signaling from a spectrum of receptors clinically validated or implicated in NV AMD pathology.

Currently approved therapies for NV AMD require frequent intravitreal injections, 8-12 times per year, to maintain optimal efficacy and vision improvement. In trials evaluating fixed quarterly dosing versus monthly dosing of ranibizumab, patients assigned to the less-frequent dosing groups gained fewer letters than patients dosed monthly (Regillo et al., 2008; Schmidt-Erfurth et al., 2011). The frequent dosing required for current therapies decreases patient adherence and increases the risk of injection-related complications. Our planned approach is to use PI3K pathway inhibitors for the treatment of retinal diseases focused on administration of a small-molecule $\mathrm{PI} 3 \mathrm{~K} / \mathrm{mTOR}$ inhibitor via intravitreal injection with an objective of needing to administer the PI3K inhibitor infrequently, ideally just once every 6 months.

We hypothesized that we could achieve such a long-acting PI3K inhibitor for retinal diseases by injecting a suspension of drug where limited solubility and dissolution would allow for sustained release. In the present work, we characterized the PI3K and mTOR biochemical potency, anti-cell migration activity, in vivo antineovascularization activity in rat eyes, and plasma and ocular pharmacokinetics of GNE947 after intravitreal injections of solution or suspension formulations in

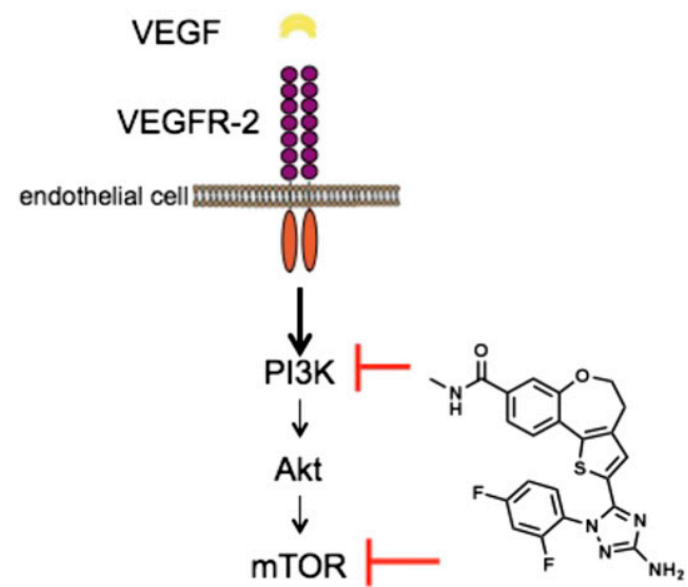

Fig. 1. GNE-947 targets $\mathrm{PI} 3 \mathrm{~K}$ and mTOR kinases to inhibit endothelial cell survival, migration, and vascular permeability induced by VEGF. Akt, Protein kinase B.
GNE-947
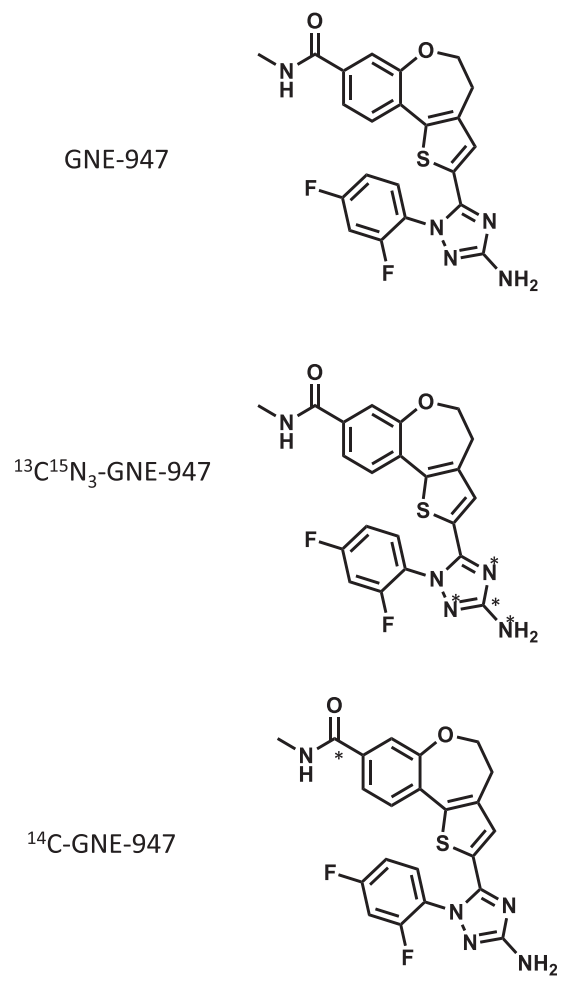

Fig. 2. Structures of GNE-947, its stable isotope-labeled form, and radioactive isotope-labeled form. The asterisk sign shows the labeled atoms.

rabbits. We also used matrix-assisted laser desorption/ionization imaging mass spectrometry (MALDI-IMS) and autoradioluminography to examine the ocular distribution and dissolution of GNE-947. The results from the present study not only are helpful in designing PI3K/mTOR inhibitors for treatment of wet AMD but also will inform programs directed at the discovery of drugs to treat other retinal diseases.

\section{Materials and Methods}

Chemicals. Ten PI3K inhibitors (Table 1) were synthesized at Genentech or Wuxi (Shanghai, China). $\left.{ }^{13} \mathrm{C}^{15} \mathrm{~N}_{3}\right] \mathrm{GNE}-947$ was synthesized by IsoSciences (King of Prussia, PA). $\left[{ }^{14} \mathrm{C}\right] \mathrm{GNE}-947$ was synthesized by Selcia (Essex, UK). Synthetic melanin was obtained from Sigma-Aldrich (St. Louis, MI) with purity of $100 \%$. All chemicals used in the experiments were of the highest available grade.

PI3K Inhibition. As previously published (Heffron et al., 2016), enzymatic activity of the class I PI3K isoforms was measured using a fluorescence polarization assay that monitors formation of the product 3,4,5-inositoltriphosphate molecule (PIP3) as it competes with fluorescently labeled PIP3 for binding to the GRP-1 pleckstrin homology domain protein. An increase in phosphatidyl inositide-3-phosphate product results in a decrease in fluorescence polarization signal as the labeled fluorophore is displaced from the GRP-1 protein binding site. Class I PI3K isoforms were purchased from Perkin Elmer or were expressed and purified as heterodimeric recombinant proteins. Tetramethylrhodamine-labeled PIP3, di-C8-phosphatidylinositol 4,5-bisphosphate, and PIP3 detection reagents were purchased from Echelon Biosciences. PI3K isoforms were assayed under initial rate conditions in the presence of $10 \mathrm{mM}$ Tris (pH 7.5), $25 \mu \mathrm{M}$ ATP, 9.75 $\mu \mathrm{M}$ phosphatidylinositol 4,5-bisphosphate, $5 \%$ glycerol, $4 \mathrm{mM} \mathrm{MgCl}_{2}, 50 \mathrm{mM}$ $\mathrm{NaCl}, 0.05 \%$ (v/v) Chaps, $1 \mathrm{mM}$ dithiothreitol, and 2\% (v/v) DMSO at the following concentrations for each isoform: $\mathrm{PI} 3 \mathrm{~K} \alpha, \beta$ at $60 \mathrm{ng} / \mathrm{ml}, \mathrm{PI} 3 \mathrm{~K} \gamma$ at $8 \mathrm{ng} / \mathrm{ml}$, and PI3K $\delta$ at $45 \mathrm{ng} / \mathrm{ml}$. After incubation for 30 minutes at $25^{\circ} \mathrm{C}$, reactions were terminated with a final concentration of $9 \mathrm{mM}$ EDTA, $4.5 \mathrm{nM}$ tetramethylrhodamine-labeled PIP3, and $4.2 \mu \mathrm{g} / \mathrm{ml} \mathrm{GRP}-1$ detector protein before reading fluorescence polarization on an Envision plate reader. Apparent $K_{\mathrm{i}}$ values were determined at a fixed concentration of ATP near the measured $K_{\mathrm{m}}$ for ATP 
TABLE 1

Potency and solubility data for studied PI3K inhibitors

\begin{tabular}{lccccc}
\hline Compounds & $\begin{array}{c}\text { PI3K } \alpha K_{\mathrm{i}} \\
\mathrm{app} \mu \mathrm{M}\end{array}$ & $\begin{array}{c}\mathrm{mTOR} K_{\mathrm{i}} \\
\mathrm{app} \mu \mathrm{M}\end{array}$ & HUVEC EC $50 \mu \mathrm{M}$ & $\begin{array}{c}\text { Solubility } \mu \mathrm{M} \\
(\mathrm{pH} 7.2)\end{array}$ & Solubility/HUVEC EC $_{50}$ \\
\hline 1 & 0.0002 & 0.026 & 0.042 & 4.2 & 100 \\
2 & 0.0007 & 0.03 & 0.061 & 26 & 426 \\
3 (GNE-947) & $<0.00005$ & 0.044 & 0.093 & 2.2 & 24 \\
4 & 0.005 & 0.022 & 0.171 & 12 & 22 \\
5 & 0.006 & 0.75 & 0.184 & 4.7 & 78 \\
6 & 0.0006 & 0.025 & 0.189 & 15 & 5.4 \\
7 & 0.00009 & 0.21 & 0.203 & 12 & 41 \\
9 & 0.018 & 0.044 & 0.303 & 12 & $<2$ \\
10 & 0.006 & 0.059 & 0.882 & 2 & $<2$ \\
\hline
\end{tabular}

for each isoenzyme and were calculated by fitting of the dose-response curves to an equation for tight-binding competitive inhibition. All apparent $K_{\mathrm{i}}$ values represent geometric means of minimum of three determinations. These assays generally produced results within 2-fold of the reported mean.

mTOR Inhibition. As previously published (Heffron et al., 2012), human recombinant mTOR (1360-2549) was expressed and purified from insect cells and assayed using a Lanthascreen fluorescence resonance energy transfer format from Invitrogen in which phosphorylation of recombinant GFP-4E-BP1 is detected using a terbium-labeled antibody to phospho-threonine 37/46 of 4EBP1. Reactions were initiated with ATP and conducted in the presence of $50 \mathrm{mM}$ Hepes (pH 7.5), 0.25 nM mTOR, 400 nM GFP-4E-BP1, $8 \mu$ M ATP, $0.01 \%$ (v/v) Tween 20, $10 \mathrm{mM} \mathrm{MnCl} 2,1 \mathrm{mM}$ EGTA, $1 \mathrm{mM}$ dithiothreitol, and $1 \%(\mathrm{v} / \mathrm{v})$ DMSO. Assays were conducted under initial rate conditions at room temperature for 30 minutes before terminating the reaction and detecting product in the presence of $2 \mathrm{nM}$ terbium labeled-anti-p4E-BP1 antibody and $10 \mathrm{mM}$ EDTA. Dose-response curves were fit to an equation for competitive tight-binding inhibition, and apparent $K_{\mathrm{i}}$ values were calculated using the determined $K_{\mathrm{m}}$ for ATP of $6.1 \mu \mathrm{M}$. All apparent $K_{\mathrm{i}}$ values represent geometric means of a minimum of two determinations. These assays generally produced results within 2 -fold of the reported mean.

Human Umbilical Vein Endothelial Cell Migration Assay. Transwell inserts (\#353097; BD Biosciences) were coated overnight with $8 \mu \mathrm{g} / \mathrm{ml}$ fibronectin (\#F1141; Sigma). In vitro human umbilical vein endothelial cells (HUVECs) (\#CC-2519; Lonza) were incubated in endothelial basal medium (\#CC-3121; Lonza) containing $0.1 \%$ bovine serum albumin for 6 hours to serumstarve the cells. HUVEC were then plated into the Transwell inserts $\left(5 \times 10^{5}\right.$ cells per well) and then incubated overnight with or without $10 \mathrm{ng} / \mathrm{ml}$ VEGF and serially diluted PI3K inhibitors (in triplicate per concentration). Positive control for this experiment was cells cultured with $10 \mathrm{ng} / \mathrm{ml}$ VEGF without PI3K inhibitors. Negative control was cells treated with $10 \mathrm{ng} / \mathrm{ml}$ VEGF and $10 \mathrm{ng} / \mathrm{ml}$ anti-VEGF antibodies (Lucentis). Cells were then fixed with methanol and stained with Sytox Green (Invitrogen). Cells on the top of the plates were scraped and washed with PBS to remove cells that did not migrate. Nuclei on the bottom of the insert were counted to number of cells that migrated. $\mathrm{The}^{\mathrm{IC}_{50}}$ value was then calculated by plotting the PI3K inhibitor concentration against the percentage of cells migrated on a graph.

Solubility. Solubility of molecules was determined according to the method described by Lin and Pease (2016).

Plasma Protein Binding. Protein binding determination was conducted at $37^{\circ}$ $\mathrm{C}$ by an equilibrium dialysis method using a Single-Use Plate Rapid Equilibrium Dialysis device with dialysis membranes that had a molecular weight cutoff of approximately $8000 \mathrm{Da}$. Equilibrium dialysis was carried out using $0.3 \mathrm{ml}$ of spiked plasma dialyzed against $0.5 \mathrm{ml}$ of blank potassium phosphate buffer $(\mathrm{pH}=$ 7.4) at $37^{\circ} \mathrm{C}$ for 6 hours. Samples were stored at approximately $-20^{\circ} \mathrm{C}$ until analysis. GNE-947 concentrations in plasma/phosphate buffer were determined using an LC-MS/MS method.

Melanin Binding. Melanin binding was determined using a method reported previously (Koeberle et al., 2003). Briefly, $2 \mathrm{ml}$ of melanin suspension at $1 \mathrm{mg} / \mathrm{ml}$ was sonicated for approximately 15 minutes and kept in a $37^{\circ} \mathrm{C}$ incubator for approximately 30 minutes prior to spiking with GNE-947. After stirring at $37^{\circ} \mathrm{C}$ for 180 minutes, $1.3 \mathrm{ml}$ of the suspension was centrifuged at $280,000 \mathrm{~g}$ for
15 minutes. Then, a $0.2-\mathrm{ml}$ aliquot of supernatant was collected into a tube containing a mixture of $0.2 \mathrm{ml}$ of blank human plasma and $0.2 \mathrm{ml}$ of blank melanin suspension $(1 \mathrm{mg} / \mathrm{ml})$. Samples were stored at approximately $-20^{\circ} \mathrm{C}$ until analysis. GNE-947 was determined using an LC-MS/MS method.

Intravenous Administration of GNE-947. The systemic pharmacokinetics of GNE-947 were evaluated after an intravenous single bolus administration of $2.5(n=8)$ or $500(n=4) \mu \mathrm{g} / \mathrm{kg}$ in male Dutch-Belted rabbits with an average of $2 \mathrm{~kg}$ b.wt. The vehicle for $2.5 \mu \mathrm{g} / \mathrm{kg}$ formulation was $10 \%$ polyethylene glycol 400 in PBS, and the vehicle used for $500 \mu \mathrm{g} / \mathrm{kg}$ formulations was $20 \%$ hydroxypropyl- $\beta$-cyclodextrin $/ 0.23 \%$ NaCl. After intravenous administration at $1 \mathrm{ml} / \mathrm{kg}$ through ear vein, approximately $800-\mu 1$ blood samples were collected from the central ear artery at 5 and 15 minutes and 1, 2, 4, 8, and 24 hours for the $2.5-\mu \mathrm{g} / \mathrm{kg}$ group and at $2,5,15$, and 30 minutes and 1,2, 4, 8, and 24 hours for the $500-\mu \mathrm{g} / \mathrm{kg}$ group. Blood samples were placed into tubes containing $\mathrm{K}_{2}$ EDTA. Blood samples were centrifuged at approximately $11,000 \mathrm{rpm}$ for approximately 5 minutes at $4^{\circ} \mathrm{C}$ to obtain plasma. The plasma samples were stored at $-80^{\circ} \mathrm{C}$ before analysis. All studies were approved by the Genentech Institutional Animal Care and Use Committee.

Intravitreal Administration of GNE-947 in Solution Formulation. The pharmacokinetics of GNE-947 were evaluated after intravitreal administration in male Dutch-Belted rabbits with an average of $2 \mathrm{~kg}$ b.wt. The vehicle for intravitreal formulation was $10 \%$ polyethylene glycol 400 in PBS. The rabbits were anesthetized with intramuscular injection of $5 \mathrm{mg} / \mathrm{kg}$ xylazine and $22 \mathrm{mg} / \mathrm{kg}$ ketamine, and then a bolus intravitreal injection of $50 \mu \mathrm{l}$ was administered to each eye at $2.5 \mu \mathrm{g}$ per eye. Blood samples were collected at 15 and 30 minutes and 1, 2, 3, 6, 12, 24, and 48 hours. Blood samples were treated as described above. Aqueous humor samples were collected at 15 and 30 minutes and 1, 2, 3, 6, 12, 24, 48, and 72 hours. After rabbits were euthanized, four eyeballs from two animals were collected through the use of staggered sampling. Vitreous humor samples were collected from the isolated eyeballs and weighed. The plasma, aqueous humor, and vitreous humor samples were stored at $-80^{\circ} \mathrm{C}$ before analysis.

Intravitreal Administration of GNE-947 in Suspension Formulation. The ocular pharmacokinetics of GNE-947 were evaluated after intravitreal administration in male Dutch-Belted rabbits with an average of $2 \mathrm{~kg}$ b.wt. The vehicle used for the intravitreal suspension formulation was sodium carboxymethylcellulose. After the rabbits were anesthetized as described above, intravitreal administration of $33.5 \mu \mathrm{g}$ per eye, $100 \mu \mathrm{g}$ per eye, and $200 \mu \mathrm{g}$ per eye at $50 \mu \mathrm{l}$ per eye were conducted. Blood samples were collected at 15 and 30 minutes; 1, 2, 4, and 6 hours; and 1, 2, 4, 8, 15, 21, 30, 45 (for all doses), 60, 73, 92 (for $100 \mu \mathrm{g}$ per eye and $200 \mu \mathrm{g}$ per eye), 105, and 162 (for $200 \mu \mathrm{g}$ per eye) days. Blood samples were treated as described above. Aqueous humor samples were collected at 6 hours and $1,2,4,8,15$, and 45 days for $33.5 \mu \mathrm{g}$ per eye; 6 hours and $1,2,4,15,45,73$, and 92 days for $100 \mu \mathrm{g}$ per eye; and 6 hours and 1, 4, 15, 45, 73, 92, and 162 days for $200 \mu \mathrm{g}$ per eye. After the rabbits were euthanized, their eyeballs were isolated at $1,4,8,15$, and 45 days for $33.5 \mu \mathrm{g}$ per eye; $1,4,15,73$, and 92 days for $100 \mu \mathrm{g}$ per eye; and 1, 8, 15, 73, 92, and 162 days for $200 \mu \mathrm{g}$ per eye. The plasma, aqueous humor, and eyeball samples were stored at $-80^{\circ} \mathrm{C}$ before analysis.

MALDI-IMS Study. As described above, intravitreal injection of GNE-947 at $1 \mathrm{mg}$ per eye in suspension was conducted in Dutch-Belted rabbits. The eyeballs 
were collected 30 days after the injection and stored at $-80^{\circ} \mathrm{C}$ before analysis Tissue sections of eyeballs at $12-\mu \mathrm{m}$ thickness were prepared using a cryostat (CM 3050 S; Leica Biosystems, Buffalo Grove IL) at $-20^{\circ} \mathrm{C}$. Tissues were spraycoated with $20 \mathrm{mg} / \mathrm{ml} \alpha$-cyano-4-hydroxycinnamic acid with a $2 \mu \mathrm{M}$ internal standard. Tissues were analyzed on a MALDI QSTAR-QqTOF MS (AB SCIEX, Foster City, CA) at $\mathrm{m} / \mathrm{z} 454 \rightarrow 397$ transition at $50-\mu \mathrm{m}$ lateral resolution. Images were processed using MALDI server 5.1.

Autoradioluminography Study. Male Dutch-Belted rabbits were administered a single intravitreal injection of $\left[{ }^{14} \mathrm{C}\right] \mathrm{GNE}-947$ at a dose of $150 \mu \mathrm{g} / 20 \mu \mathrm{Ci}$ per eye in suspension as described before into each eye. After animals were euthanized at $1,15,30$, and 60 days, their heads were sectioned at $40-\mu \mathrm{m}$ thickness using a Leica CM3600 cryomicrotome and analyzed by quantitative autoradioluminography.

LC-MS/MS Analysis. Sample analysis was carried out with a Shimadzu Nexera high performance liquid chromatography system (Columbia, MD) coupled to a Sciex API 5500 mass spectrometer equipped with a turboelectrospray interface in the positive ionization mode. The aqueous mobile phase was water with $10 \mathrm{mM}$ ammonium formate (A), and the organic mobile phase was methanol (B). The gradient was $40 \%$ B between 0 and 0.4 minutes, linearly increased to $85 \%$ B between 0.4 and 1.0 minutes, further increased to $90 \%$ B between 1.0 and 1.1 minutes, maintained at $90 \%$ between 1.1 and 1.7 minutes, decreased to $40 \%$ B between 1.7 and 2.1 minutes, and maintained at $40 \% \mathrm{~B}$ between 2.1 and 2.8 minutes. The flow rate was $1.25 \mathrm{ml} / \mathrm{min}$, and the cycle time (injection to injection including instrument delays) was approximately 3.6 minutes. A volume of $25 \mu \mathrm{l}$ of the final extract was injected onto the analytical Agilent Zorbax SB-C18 column $(50 \times 2.1 \mathrm{~mm}, 5 \mu \mathrm{m})$.

Quantitation of GNE-947 was carried out using the multiple reaction monitoring (MRM) transition $\mathrm{m} / \mathrm{z} 454.2 \rightarrow 367.1$ for GNE-947 and $\mathrm{m} / \mathrm{z} 458.2$ $\rightarrow 401.1$ for internal standard $\left[{ }^{13} \mathrm{C}^{15} \mathrm{~N}_{3}\right]$ GNE-947. The choice of product ion $\mathrm{m} / \mathrm{z}$ 367.1 over $\mathrm{m} / \mathrm{z} 397.1$ for GNE-947 MRM is to avoid the interference from the sample matrix while not sacrificing much signal. The signal intensity for MRM $\mathrm{m} / \mathrm{z} 454 \rightarrow 367$ is about $70 \%$ of that for MRM m/z $454 \rightarrow 397$ transition. The optimized instrument conditions included a source temperature of $600^{\circ} \mathrm{C}$, a curtain gas pressure of $15 \mathrm{psi}$, a nebulizing gas (GS1) pressure of $60 \mathrm{psi}$, a heating gas (GS2) pressure of $60 \mathrm{psi}$, and a collision energy of $45 \mathrm{~V}$ for both GNE-947 and $\left[{ }^{13} \mathrm{C}^{15} \mathrm{~N}_{3}\right]$ GNE-947. IonSpray needle voltage was set at $4000 \mathrm{~V}$. LC-MS/MS data were acquired and processed using Analyst software (version 1.5.2). The calibration curve for quantitation of GNE-947 was constructed by plotting the analyte (GNE-947) to internal standard $\left(\left[{ }^{13} \mathrm{C}^{15} \mathrm{~N}_{3}\right] \mathrm{GNE}-947\right)$ peak area ratios versus the nominal concentration of the analyte with a weighted $1 / \times 2$ linear regression.

Aliquots of $150 \mu \mathrm{l}$ of plasma samples, standards, and quality controls were transferred to wells in the 96-well plate. In all, $25 \mu 1$ of internal standard $(2.25 \mathrm{ng} / \mathrm{ml})$ was added to each sample, followed by the addition of $25 \mu \mathrm{l}$ of $5 \%$ ammonium hydroxide. The samples were vortexed for 1 minute and centrifuged at $1600 \mathrm{~g}$ for 2 minutes to force all droplets to the bottom of the wells. The entire sample was loaded to an supported liquid extraction plate. The analytes were eluted by $2 \times$ $600 \mu \mathrm{l}$ of methyl tert-butyl ether to a 96-well Axygen round-bottom plate. The eluent was evaporated to dryness with $\mathrm{N}$ at $40^{\circ} \mathrm{C}$ and reconstituted with $80 \mu \mathrm{l}$ of methanol:water (40:60; v:v) solution. The whole plate was vortexed and centrifuged again. In total, $10 \mu$ l of aqueous humor or vitreous humor was mixed with $25 \mu \mathrm{l}$ of internal standard and $35 \mu \mathrm{l}$ of methanol:water (40:60; v:v) solution. The eyeballs were cut into species with scissors and homogenized with glass beater homogenizer. The $20 \mu \mathrm{l}$ of homogenate was mixed with $25 \mu \mathrm{l}$ of internal standard and $1000 \mu \mathrm{l}$ of methanol:water solution. The mixture was vortexed and centrifuged. Then, $25 \mu \mathrm{l}$ of supernatant was injected into the LC-MS/MS system for sample analysis. The lower and upper limits of quantitation of the assay were 5 and $2500 \mathrm{pg} / \mathrm{ml}$, respectively.

Data Analysis. Noncompartmental pharmacokinetic analyses were conducted using Phoenix WinNonlin version 6.3 (Pharsight Corporation, Mountain View, CA). Nominal doses and sampling times were used. Concentration values below the lower limit of quantitation at the end of the profile were ignored for pharmacokinetic analysis.

Compartmental pharmacokinetic analyses were constructed using SAAM II version 2.3.1.1 (The Epsilon Group, Charlottesville, VA). All parameters were estimated by fitting the pharmacokinetic models to the average of the observed data at each time point. Estimates of all parameters are presented as the parameter estimate and the percent S.E.
Model for Intravenous Bolus Injection. A two-compartment model (Fig. 3A) was used to model GNE-947 plasma concentrations after intravenous administration as described by mass balance eqs. 1 and 2:

$$
\begin{gathered}
\mathrm{V}_{\mathrm{c}} \mathrm{dC}_{\mathrm{c}} / \mathrm{dt}=-\left(\mathrm{Cl}_{\mathrm{d}}+\mathrm{Cl}_{\mathrm{p}}\right) \mathrm{C}_{\mathrm{c}}+\mathrm{Cl}_{\mathrm{d}} \mathrm{C}_{\mathrm{t}} \\
\mathrm{V}_{\mathrm{t}} \mathrm{dC}_{\mathrm{t}} / \mathrm{dt}=\mathrm{Cl}_{\mathrm{d}}\left(\mathrm{C}_{\mathrm{c}}-\mathrm{C}_{\mathrm{t}}\right)
\end{gathered}
$$

where $C_{c}$ and $C_{t}$ are the concentrations of GNE-947 in the central and peripheral compartments, respectively; $\mathrm{V}_{\mathrm{c}}$ and $\mathrm{V}_{\mathrm{t}}$ are the volume of distribution in the central and peripheral compartments, respectively; and $\mathrm{Cl}_{\mathrm{p}}$ and $\mathrm{Cl}_{\mathrm{d}}$ are the elimination clearance from the central compartment and distribution clearance between the compartments, respectively.

Model for the Intravitreal Injection of the Solution Formulation. A fivecompartment model in Fig. 4A was used to fit the drug concentrations in the plasma, vitreous humor, and aqueous humor after intravitreal injection of the solution formulation. The drug in vitreous humor was described by a vitreous humor compartment (VH Cmpt) and a binding compartment (binding Cmpt) as described by eqs. 3 and 4 :

$$
\begin{gathered}
\mathrm{V}_{\mathrm{vh}} \mathrm{dC}_{\mathrm{vh}} / \mathrm{dt}=-\left(\mathrm{Cl}_{\mathrm{vp}}+\mathrm{Cl}_{\mathrm{va}}+\mathrm{Cl}_{\mathrm{vb}}\right) \mathrm{C}_{\mathrm{vh}}+\mathrm{K}^{*} \mathrm{~A}_{\text {binding }} \\
\mathrm{dA}_{\text {binding }} / \mathrm{dt}=\mathrm{Cl}_{\mathrm{vb}} \mathrm{C}_{\mathrm{vh}}-\mathrm{K}^{*} \mathrm{~A}_{\text {binding }}
\end{gathered}
$$

where $V_{v h}$ is the volume of distribution for the vitreous humor compartment; $C_{v h}$ and $\mathrm{A}_{\text {binding }}$ are the concentrations in vitreous humor and amount in the binding compartment, respectively; $\mathrm{Cl}_{\mathrm{vp}}, \mathrm{Cl}_{\mathrm{va}}$, and $\mathrm{Cl}_{\mathrm{vb}}$ are the clearance from the vitreous humor to plasma, aqueous humor, and binding compartment, respectively; and $\mathrm{K}$ is the rate constant from the binding compartment to vitreous humor compartment.

The drug in aqueous humor compartment (AH Cmpt) is described by eq. 5 :

$$
\mathrm{V}_{\mathrm{ah}} \mathrm{dC}_{\mathrm{ah}} / \mathrm{dt}=\mathrm{Cl}_{\mathrm{va}} \mathrm{C}_{\mathrm{vh}}-\mathrm{Cl}_{\mathrm{ah}} * \mathrm{C}_{\mathrm{ah}}
$$

A

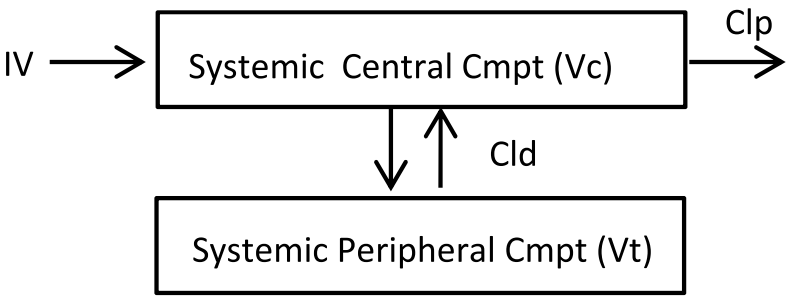

B
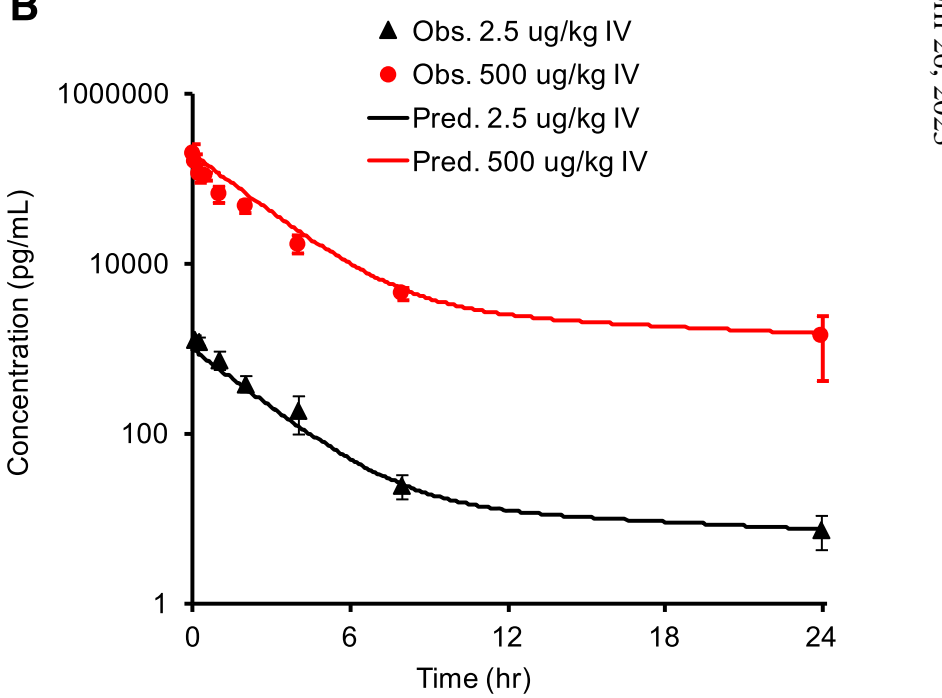

Fig. 3. GNE-947 plasma concentration-time profiles after a single IV bolus dose of $25 \mu \mathrm{g} / \mathrm{kg}$ (red) or $500 \mu \mathrm{g} / \mathrm{kg}$ (black) in rabbits. (A) is a two-compartmental model to describe the plasma PK. The lines in (B) represent the predicted concentrations from the model in (A). The PK parameters are listed in Table 3. IV, intravenous. 
A
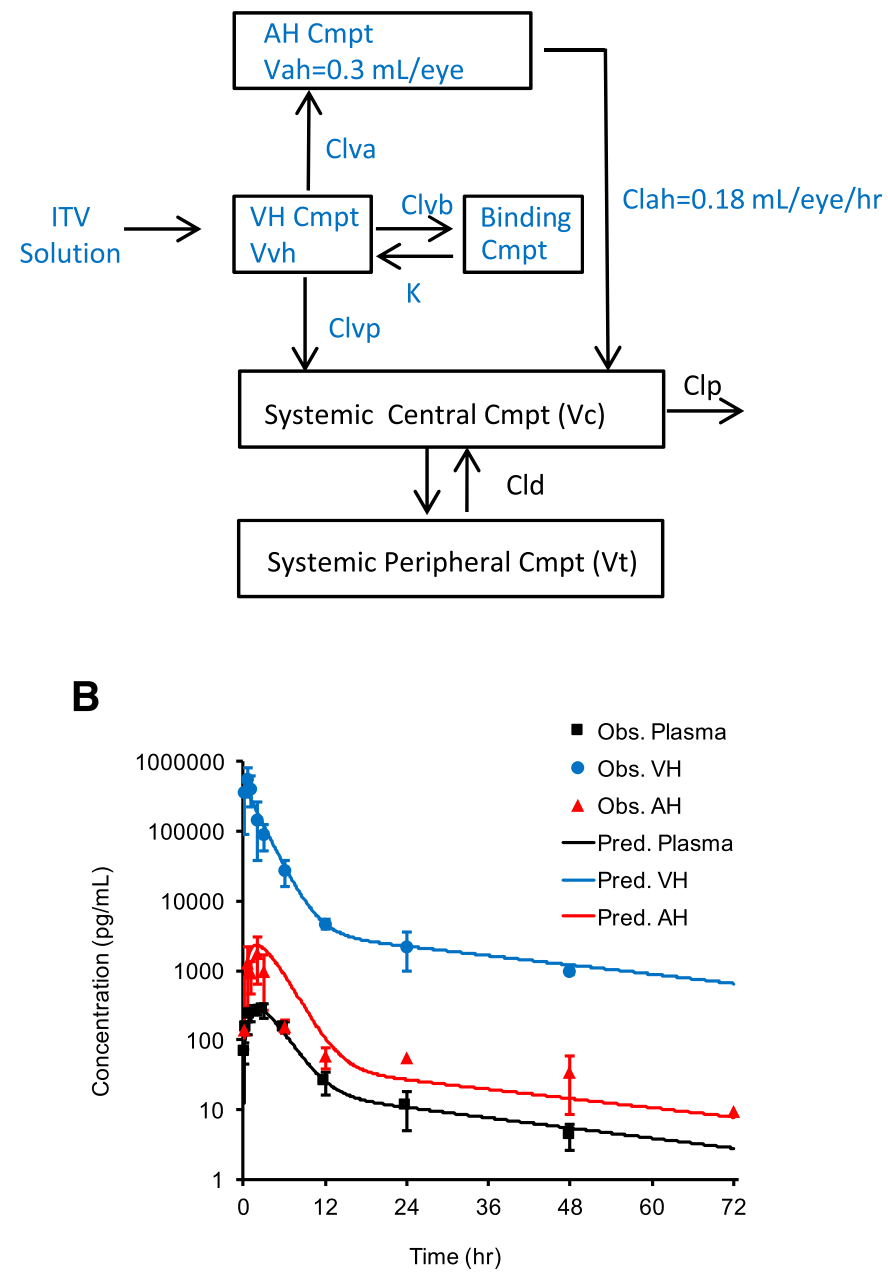

Fig. 4. (A) A 5-compartmental model to describe the plasma and ocular PK for the solution formulation. GNE-947 plasma (black), aqueous humor (red), and vitreous humor (blue) concentration vs. time after a single intravitreal dose of $2.5 \mu \mathrm{g}$ per eye in a solution formulation. The lines in (B) represent the predicted concentrations from the model in (A). The PK parameters are listed in Table 4. ITV, intravitreal; Obs, observed; Pred, predicted.

where $\mathrm{V}_{\mathrm{ah}}$ is the volume of the aqueous humor compartment, which was set as the physiologic volume of $0.3 \mathrm{ml}$ per eye for rabbits (Del Amo and Urtti, 2015); $\mathrm{C}_{\mathrm{ah}}$ is the concentration in the aqueous humor; and $\mathrm{Cl}_{\mathrm{ah}}$ is the clearance from the aqueous humor to plasma, which was set as the physiologic turnover rate of $0.18 \mathrm{ml} / \mathrm{h}$ per eye for rabbits (Del Amo and Urtti, 2015).

The drug in systemic central compartment was modeled by eq. 6 :

$$
\mathrm{V}_{\mathrm{c}} \mathrm{dC}_{\mathrm{c}} / \mathrm{dt}=-\left(\mathrm{Cl}_{\mathrm{d}}+\mathrm{Cl}_{\mathrm{p}}\right) \mathrm{C}_{\mathrm{c}}+\mathrm{Cl}_{\mathrm{d}} \mathrm{C}_{\mathrm{t}}+2\left(\mathrm{Cl}_{\mathrm{vp}} \mathrm{C}_{\mathrm{vh}}+\mathrm{Cl}_{\mathrm{ah}} \mathrm{C}_{\mathrm{ah}}\right)
$$

The drug in the systemic peripheral compartment was described in the same way as eq. 2 . Since systemic clearance and volume of distribution are determined by the physicochemical properties of the compound and the physiologic system, the same systemic model structure, clearance, and volume of distribution parameters were used for the intravenous and intravitreal administration of different formulations.

Modeling for the Intravitreal Injection of Suspension Formulation. After intravitreal injection of GNE-947 in suspension formulation, the plasma concentrations showed a biphasic curve with similar maximal concentration at the three dose levels (Supplemental Fig. 4) but dose-proportional concentrations at later time points. We hypothesized that the $50-\mu 1$ suspension formulation of GNE-947 split into two pools after intravitreal injection. The fast-release pool was composed of solubilized drug at the three dose levels, resulting in similar maximal concentration in the plasma. The slow-release pool compartment was composed of undissolved drug particles. It was assumed that the dose was split into a fastrelease pool and a slow-release pool after injection, as described by eqs. 7-9:

$$
\begin{aligned}
& \text { for } 33.5 \text { ug per eye dose level: Dose } \\
& \text { slow } \\
& \text { for } 100 \mathrm{ug} \text { per eye dose level: Dose } \\
& \text { slow } \\
& \text { for } 200 \mathrm{ug} \text { uger eye dose level: } \text { Dose }_{\text {fast }} \\
& \text { flow } \\
& =200-\text { Dose }_{\text {fast }}
\end{aligned}
$$

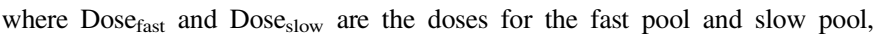
respectively; Dose $_{\text {fast }}$ was a constant and was estimated from the observed data using Split Input Function in SAAMII program.

The amount of drug in the fast and slow pools was described by eqs. 10 and 11:

$$
\begin{gathered}
\mathrm{dA}_{\text {fast }} / \mathrm{dt}=-\left(\mathrm{K}_{1}+\mathrm{K}_{2}\right) \mathrm{A}_{\text {fast }}+\mathrm{K}_{3}\left(\mathrm{~A}_{\text {slow }}\right)^{2 / 3} \\
\mathrm{dA}_{\text {slow }} / \mathrm{dt}=-\mathrm{K}_{3}\left(\mathrm{~A}_{\text {slow }}\right)^{2 / 3}
\end{gathered}
$$

where $K_{1}$ and $K_{2}$ are the rate constants from the fast compartment to the systemic central compartment and aqueous humor compartment, respectively; $\mathrm{K}_{3}$ is the rate constant from the slow pool to the fast pool (Fig. 5A). The rationale for selection of two-third exponent for the slow pool mass will be discussed in detail in the Discussion section.

The drug in the aqueous humor compartment was described by eq. 12 :

$$
\mathrm{V}_{\mathrm{ah}} \mathrm{dC} \text { ah } / \mathrm{dt}=\mathrm{K}_{2} \mathrm{~A}_{\text {fast }}-\mathrm{Cl}_{\mathrm{ah}} * \mathrm{C}_{\mathrm{ah}}
$$

The drug in the plasma central compartment is described by eq. 13:

$$
\mathrm{V}_{\mathrm{c}} \mathrm{dC}_{\mathrm{c}} / \mathrm{dt}=-\left(\mathrm{Cl}_{\mathrm{d}}+\mathrm{Cl}_{\mathrm{p}}\right) \mathrm{C}_{\mathrm{c}}+\mathrm{Cl}_{\mathrm{d}} \mathrm{C}_{\mathrm{t}}+2\left(\mathrm{~K}_{1} \mathrm{~A}_{\text {fast }}+\mathrm{Cl}_{\mathrm{ah}} * \mathrm{C}_{\mathrm{ah}}\right)
$$

The drug in the systemic peripheral compartment is described in the same way as eq. 2 .

In Vivo Laser-Induced Choroidal Neovascular Model. Rats were anesthetized by intraperitoneal injection of a mixture of ketamine and xylazine. Pupils were dilated using a single drop of $1 \%$ tropicamide. Animals were placed on a platform. Six burns of $100 \mu \mathrm{m}$ at 532-nm diode laser photocoagulation with $120-\mathrm{mW}$ power for a 100-millisecond duration were delivered to the retina of the right eye using the slit lamp delivery system of an OcuLight GL Photocoagulator (Iridex, Mountain View, CA) and a handheld cover slide as a contact lens. Burns were performed one to two disc diameters from the optic nerve in 2, 4, 6, 8, 10, and 12 o'clock positions. Production of a bubble on the retina at the time of laser, which indicated rupture of Bruch's membrane, was an important factor in obtaining choroidal neovascular (CNV), so only burns in which a bubble was produced were included in the study. Animals with burns resulting in subretinal hemorrhage were excluded from the study.

All animals undergoing the CNV procedure were administered buprenorphine as an analgesic subcutaneously every 8-12 hours for 2 days after laser treatment. Each dose of GND-947 was given prior to recovery from anesthesia.

Under anesthesia, Betadine 5\% Sterile Ophthalmic Prep Solution (Alcon Laboratories, Inc.) for the eye was used to apply antiseptic to the surface area around and onto the eye 5 minutes before the injection. A 0.5 -mm-tip tungsten pin (10130-20; Fine Science Tools) was used to create an opening at the posterior limbus. Care was used to avoid damage to the lens. A 30-gauge Hamilton needle and syringe were used to deliver $5 \mu \mathrm{l}$ of $50 \mu \mathrm{g}$ or $100 \mu \mathrm{g}$ GNE-947 in solution formulation or vehicle only through the resulting entrance site. The single maximum volume of each single intravitreal injection volume for each rat would not exceed $5 \mu \mathrm{l}$. Four doses of vehicle or GNE-947 were given on days $0,3,7$, and 10 after laser injury. A postoperative application of povidone-iodine solution was given to ensure that the eye was properly disinfected after injection. All instruments and solutions used in this procedure were either sterile or sterilized, and aseptic techniques were used in the injection procedure. In total, $0.01-0.05 \mathrm{mg} / \mathrm{kg}$ of buprenorphine was given to the animals for 2 days after the injection. Neomycin and polymyxin B sulfate and bacitracin zinc ophthalmic ointment were applied to the injected eye postinjection.

Animal health status was monitored twice daily, and body weights were measured daily for the first 3 days of dosing and twice per week if no body weight loss was observed after. The animals were weighed daily if $15 \%$ b.wt. loss was observed and were sacrificed if $20 \%$ b.wt. loss was observed.

At 14 days after laser injury, animals were injected with $1 \mathrm{ml}$ of $25 \mathrm{mg} / \mathrm{ml}$ Fluorescein Dextran (FD2000S; Sigma) through tail vein injection. At 5 minutes 


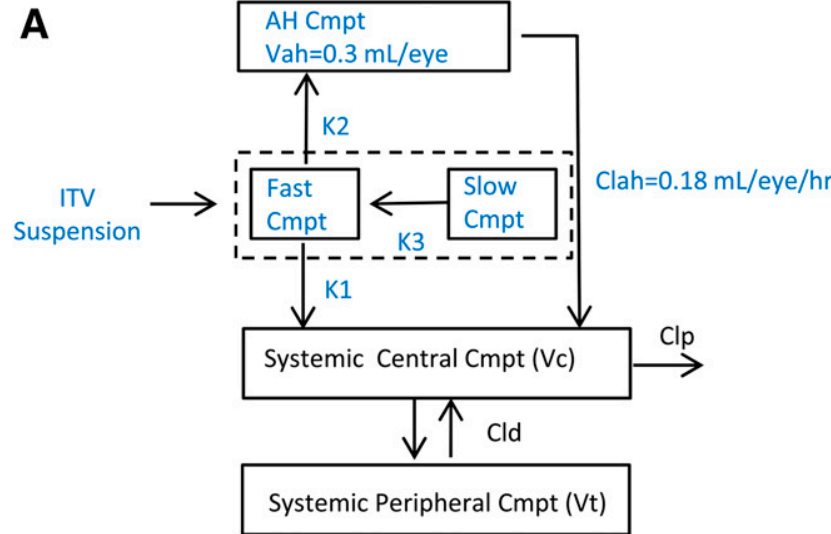

B

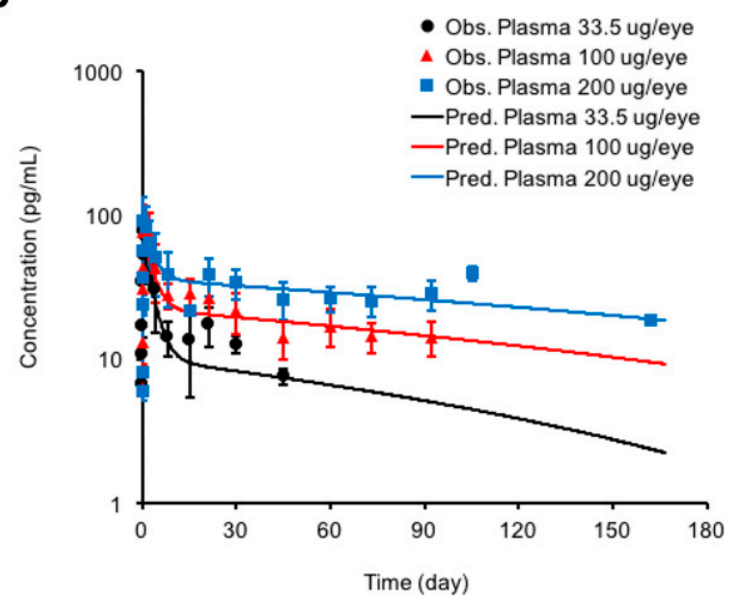

C

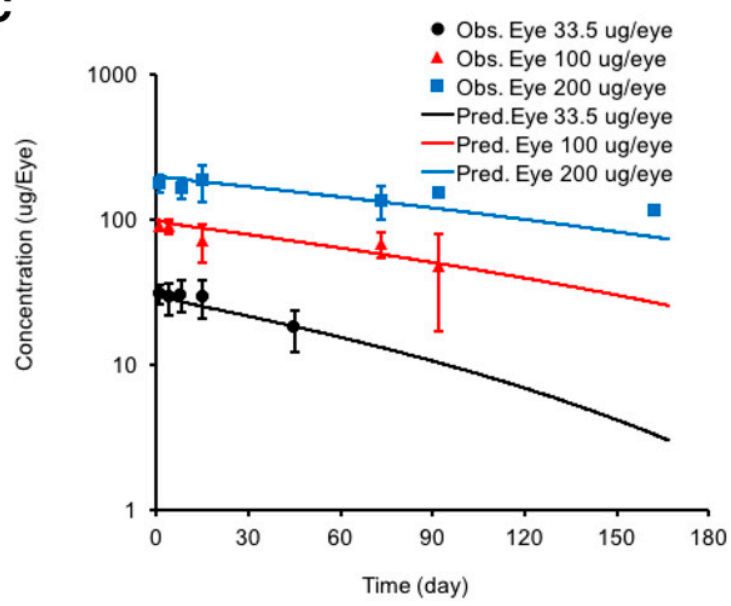

D

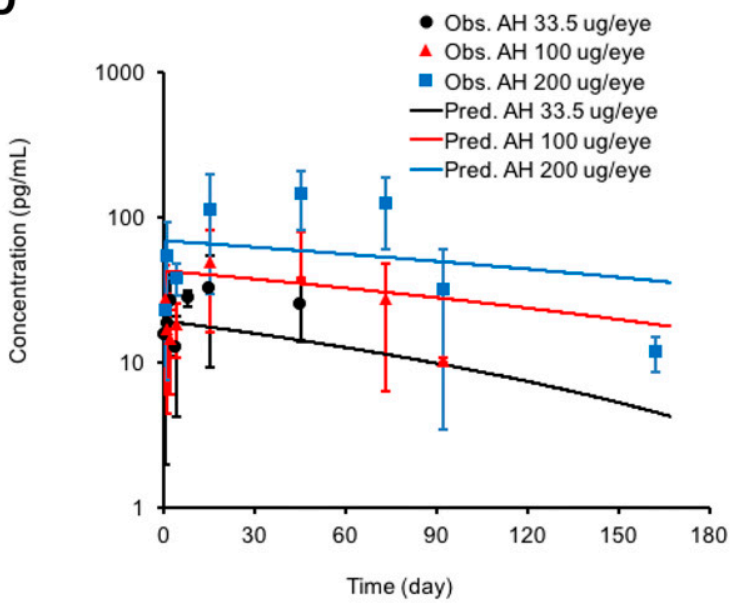

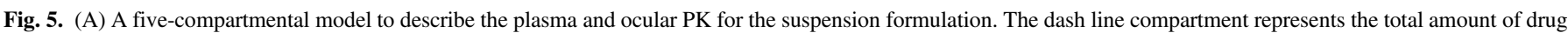

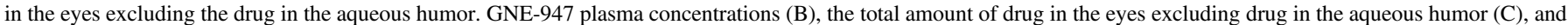

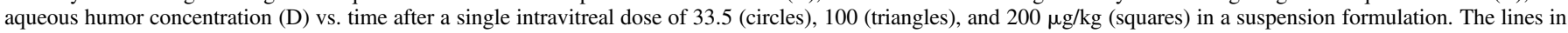
(B-D) represent the predicted concentrations from the model in (A). The PK parameters are listed in Table 5. ITV, intravitreal.

after the tail vein injection, the animal was euthanized by $\mathrm{CO}_{2}$ inhalation to effect. The eyes were removed and fixed in freshly prepared $4 \%$ paraformaldehyde in PBS for 1 hour. The cornea, lens, and retina were removed, and the entire choroid with eye cup was carefully dissected. Radial cuts (four to seven, average five) were performed from the edge to the equator, with care not to cut the laser injury sites, and the eyecup was flat-mounted and observed to fluorescence microscopy.

\section{Results}

PI3K/mTOR Inhibition, HUVEC Migration Inhibition, and Solubility of $\mathbf{1 0}$ Molecules. The inhibitory potency of a selection of 10 molecules against PI $3 \mathrm{~K} \alpha$ and mTOR was evaluated along with the potency against cell migration in an HUVEC assay. These data, along with the solubility of the 10 molecules, are presented in Table 1 . Of the 10 molecules, entries 4-10 had HUVEC migration $\mathrm{EC}_{50}$ values that were greater than $100 \mathrm{nM}$ and were not selected for further evaluation because of low potency. The remaining three molecules were deemed to have adequate potency in that cellular assay. Although entries 1 and 2 were the most potent molecules in the HUVEC assay, they led to solubility/cell $\mathrm{EC}_{50}$ ratios greater than we desired (vide infra). Therefore, entry 3 (GNE-947) was selected for further evaluation.

GNE-947 Extensively Binds to Plasma Proteins and Melanin. The binding of GNE-947 to rabbit plasma proteins and melanin under various concentrations is presented in Table 2. The unbound fraction of GNE-947 in rabbit plasma was about 0.040 in the concentration range of 0.01-10 $\mu \mathrm{M}$. In $1 \mathrm{mg} / \mathrm{ml}$ of melanin suspension, the unbound fraction was from 0.0030 to 0.0044 in GNE-947 concentration range of $0.1-10$ $\mu \mathrm{M}$. These results show that GNE-947 extensively binds to plasma proteins and melanin and that its binding is concentration-independent at concentrations under $10 \mu \mathrm{M}$.

GNE-947 Shows Plasma Terminal $t_{1 / 2}$ of 9.11-9.59 Hours after a Single Intravenous Bolus Dose in Rabbits. The plasma concentrations after $2.5-$ or $500-\mu \mathrm{g} / \mathrm{kg}$ intravenous bolus dose are presented in Fig. 3B. Using noncompartment analysis, the estimated terminal $t_{1 / 2}$ from the mean data were 9.11 and 9.59 hours for 2.5 and $500 \mu \mathrm{g} / \mathrm{kg}$, respectively (Table 6). The plasma concentration-time profiles after intravenous dosing showed a biphasic curve. Therefore, a twocompartment model shown in Fig. 3A was used to fit the observed data at $2.5-$ and $500-\mu \mathrm{g} / \mathrm{kg}$ dose levels simultaneously. The model fits well for the observed data from both doses. The estimated compartmental PK parameters are listed in Table 3. These systemic PK parameters were used as fixed values after ocular PK modeling because systemic clearance and volume of distribution are determined by the physicochemical properties of the compound and the physiologic system.

GNE-947 Shows Similar Plasma and Vitreous Humor Terminal $t_{1 / 2}$ of 14.4-16.3 Hours after Intravitreal Injection of a Solution 
TABLE 2

Free fraction of GNE-947 in rabbit plasma and melanin suspension (mean \pm S.D., $n=3$ )

\begin{tabular}{lcc}
\hline $\begin{array}{l}\text { Conc. } \\
(\mu \mathrm{M})\end{array}$ & Plasma & Melanin Suspension \\
\hline 0.01 & $0.040 \pm 0.000$ & $\mathrm{NC}$ \\
0.1 & $\mathrm{NC}$ & $0.0030 \pm 0.0001$ \\
0.3 & $0.039 \pm 0.002$ & $0.0032 \pm 0.0005$ \\
1 & $\mathrm{NC}$ & $0.0039 \pm 0.0004$ \\
3 & $\mathrm{NC}$ & $0.0044 \pm 0.0013$ \\
10 & $0.043 \pm 0.005$ & $0.0038 \pm 0.0006$ \\
\hline
\end{tabular}

NC, studies were not conducted.

Formulation in Rabbit Eyes. The plasma, vitreous humor, and aqueous humor drug concentrations after a single intravitreal injection of GNE-947 at $2.5 \mu \mathrm{g}$ per eye in a solution formulation are presented in Fig. 4B. Using a noncompartment analysis, the estimated terminal $t_{1 / 2}$ from the mean data were $14.4,16.3$, and 23.2 hours for plasma, vitreous humor, and aqueous humor, respectively (Table 6). The concentration-time profiles in the plasma, vitreous humor, and aqueous humor are similar. The estimated area under the curves (AUCs) from time zero to infinity were $2.21 \times 10^{3}, 1.16 \times 10^{6}, 7.98 \times 10^{3} \mathrm{~h}^{*} \mathrm{pg} / \mathrm{ml}$, respectively. Therefore, the AUC in vitreous humor was 145 -fold higher than the aqueous humor, and the AUC in aqueous humor was 3.6-fold higher than the plasma.

The concentration-time profile in vitreous humor showed a biphasic curve, indicating that the compound had a distribution phase followed by an elimination phase. Because the observed concentrations in the vitreous humor were 100-fold higher than the total plasma concentrations (Fig. 4B) and 2500-fold higher than the free plasma concentrations because of its plasma free fraction of 0.040 , the biphasic shape of the vitreous humor concentrations in Fig. 4B was not believed to be due to redistribution of the compound from systemic circulation, and the effect of plasma concentrations on vitreous humor concentrations was negligible. The aqueous humor concentrations were similar to or higher than the total plasma concentrations (Fig. 4B) and were 25-fold higher than the free plasma concentration; therefore, the effect of plasma concentration on the aqueous humor concentrations was also negligible. Based on the observed results, a model shown in Fig. 4A including two compartments for the systemic circulation, two compartments for the vitreous humor, and one compartment for the aqueous humor was proposed to describe the observed concentrations. This model describes the observed data well (Fig. 4B). The estimated pharmacokinetic parameters are listed in Table 4.

GNE-947 Shows Similar Plasma and Vitreous Humor Terminal $t_{1 / 2}$ up to 6 Months in the Vitreous Humor after Intravitreal Injection of a Suspension Formulation in Rabbit Eyes. After intravitreal injection of GNE-947 at 33.5, 100, or $200 \mu \mathrm{g}$ per eye in suspension formulation in the inferior temporal region of the eye, the test article appeared bright white and also typically appeared as a primarily focal mass. Some diffusion for a short distance was observed around the main mass of the material.

The plasma, aqueous humor concentrations, and amount in the eyes after intravitreal injection of GNE-947 are presented in Fig. 5. The plasma terminal $t_{1 / 2}$ were 705 (29 day), 1760 (74 day), and 5250 hours (219 day) at $33.5 \mu \mathrm{g}$ per eye, $100 \mu \mathrm{g}$ per eye, and $200 \mu \mathrm{g}$ per eye at $50 \mu \mathrm{l}$ per eye, respectively (Table 6 ). The terminal $t_{1 / 2}$ for the amount of drug in the eyes were 1100 (46 day), 3440 (143 day), and 4600 hours (191 day) at $33.5 \mu \mathrm{g}$ per eye, $100 \mu \mathrm{g}$ per eye, and $200 \mu \mathrm{g}$ per eye at $50 \mu \mathrm{l}$ per eye, respectively (Table 6). Because there was a large variability and lack of terminal phase for the aqueous humor concentrations, the $t_{1 / 2}$ for aqueous humor were not calculated.
TABLE 3

GNE-947 pharmacokinetic parameters after a single intravenous dose at 25 or 500 $\mu \mathrm{g} / \mathrm{kg}$ in rabbits

\begin{tabular}{llrr}
\hline Parameter & \multicolumn{1}{c}{ Unit } & Value & CV\% \\
\hline $\mathrm{Cl}$ & Milliliters per hour per kilogram & 1139 & 3.87 \\
$\mathrm{Cl}_{\mathrm{d}}$ & Milliliters per hour per kilogram & 275 & 8.27 \\
$\mathrm{~V} 1$ & Milliliters per kilogram & 2645 & 3.04 \\
$\mathrm{~V} 2$ & Milliliters per kilogram & 6439 & 40.0
\end{tabular}

The model presented in Fig. 5A described the observed plasma concentrations and the amount of drug in the eye reasonably well (Fig. 5, B and C). Since the one-compartment model can adequately describe the aqueous humor concentration-time profile after an intravitreal injection of solution formulation (Fig. 4B, red line), the one-compartment model was used for aqueous humor compartment. There was a large variability and lack of a clear terminal elimination phase for the aqueous humor drug concentrations; the model was not able to describe the observed data well, but it captures the general trend of the data (Fig. 5D). The estimated pharmacokinetic parameters are listed in Table 5.

MALDI-IMS Shows Nonhomogeneous Distribution of GNE-947 in Vitreous Humor 30 Days after Intravitreal Injection of a Suspension Formulation in Rabbit Eyes. GNE-947 distribution in the eye tissues using MALDI-IMS technology is presented in Fig. 6. The MALDI-IMS image shows that most of GNE-947 was in the vitreous humor. In the vitreous humor, the compound was not homogeneously distributed. Some areas in the vitreous humor show white color, which indicates that the drug concentration was low, but other areas show dark blue or black color, which indicates high drug concentrations. Low drug concentration was associated with the surface of the lens and indicated a lack of drug penetration inside the lens.

Autoradioluminographs Show GNE-947 was Localized at the Injection Site in Vitreous Humor for 15-60 days after Intravitreal Injection of Suspension Formulation in Rabbit Eyes. GNE-947 distribution in the eyes using autoradioluminography is presented in Figs. 7 and 8. The drug generally remained in the inferior temporal portion of the vitreous cavity where eyes were dosed. On day 1 , most of the injected drug stayed at the injection sites, with a small amount distributed into the vitreous humor near the injection sites. Distal to the injection sites, the drug concentration was very low. GNE-947 was present on the surface of the lens, but no drug was observed to penetrate inside the lens (Fig. 7A; Fig. 8A). On day 15 to day 60, most of the drug in the eyes remained at the injection site, with a negligible amount in the vitreous humor (Fig. 7D; Fig. 8B). Interestingly, on day 15, the drug

\section{TABLE 4}

GNE-947 pharmacokinetic parameters after a single intravitreal injection at $2.5 \mu \mathrm{g}$ per eye in a solution formulation in rabbit eyes

\begin{tabular}{|c|c|c|c|}
\hline Parameter & Unit & Value & $\mathrm{CV} \%$ \\
\hline $\mathrm{Cl}$ & Milliliters per hour per kilogram & 1139 & Fixed $^{a}$ \\
\hline $\mathrm{Cl}_{\mathrm{d}}$ & Milliliters per hour per kilogram & 275 & Fixed $^{a}$ \\
\hline V1 & Milliliters per kilogram & 2645 & Fixed $^{a}$ \\
\hline $\mathrm{V} 2$ & Milliliters per kilogram & 6439 & Fixed $^{a}$ \\
\hline $\mathrm{Cl}_{\mathrm{ah}}$ & Milliliters per eye & 0.18 & Fixed $^{b}$ \\
\hline $\mathrm{V}_{\mathrm{ah}}$ & Milliliters per eye & 0.3 & Fixed $^{b}$ \\
\hline $\mathrm{Cl}_{\mathrm{vp}}$ & Milliliters per hour per eye & 0.408 & 6.07 \\
\hline $\mathrm{Cl}_{\mathrm{va}}$ & Milliliters per hour per eye & 0.000398 & 24.7 \\
\hline $\mathrm{Cl}_{\mathrm{vb}}$ & Milliliters per hour per eye & 0.029 & 28.9 \\
\hline $\mathrm{K}$ & Hours $^{-1}$ & 0.0578 & 17.1 \\
\hline Vvh & Milliliters per eye & 5.19 & 12.4 \\
\hline
\end{tabular}

${ }^{a}$ Results from intravenous bolus PK modeling in Fig. 3 .

${ }^{b}$ Physiologic value. 
TABLE 5

GNE-947 pharmacokinetic parameters after a single intravitreal injection at 33.5 , 100 , or $200 \mu \mathrm{g}$ per eye in a suspension formulation in rabbit eyes

\begin{tabular}{|c|c|c|c|}
\hline Parameter & Unit & Value & $\mathrm{CV} \%$ \\
\hline $\mathrm{Cl}$ & Milliliters per hour per kilogram & 1139 & Fixed $^{a}$ \\
\hline $\mathrm{Cl}_{\mathrm{d}}$ & Milliliters per hour per kilogram & 275 & Fixed $^{a}$ \\
\hline V1 & Milliliters per kilogram & 2645 & Fixed $^{a}$ \\
\hline $\mathrm{V} 2$ & Milliliters per kilogram & 6439 & Fixed $^{a}$ \\
\hline $\mathrm{Cl}_{\mathrm{ah}}$ & Milliliters per eye & 0.18 & Fixed $^{b}$ \\
\hline $\mathrm{V}_{\mathrm{ah}}$ & Milliliters per eye & 0.3 & Fixed $^{b}$ \\
\hline Dose $_{\text {fast }}$ & Micrograms per eye & 4.54 & 18.8 \\
\hline $\mathrm{K}_{1}$ & Hours $^{-1}$ & 0.0150 & 20.0 \\
\hline $\mathrm{K}_{2}$ & Hours $^{-1}$ & 0.0000366 & 11.9 \\
\hline $\mathrm{K}_{3}$ & Hours $^{-1}$ & 0.122 & 6.17 \\
\hline
\end{tabular}

${ }^{a}$ Results from intravenous bolus PK modeling in Fig. 3 .

${ }^{b}$ Physiologic value.

distributed inside the lens but did not reach the center of the lens (Fig. 7D); however, by day 60, the drug had penetrated to the center of the lens (Fig. 8B).

Intravitreal Injection of GNE-947 was Efficacious in Laser-Induced CNV Rat Eyes. After argon laser-induced damage to the rat choroid, neovascularization takes place. This neovascularization models some characteristics of vascular pathology in patients with wet AMD. Immediately after laser-induced damage, GNE-947 was administered by intravitreal injection at 50 or $100 \mu \mathrm{g}$ per eye (Fig. 9A) and again on days 3,7 , and 10 . On day 14 of the study, tissues were harvested, and the extent of neovascularization was determined by microscopy evaluation by measuring the area of lesion. Compared with the vehicle controls, the animals treated with either 50 or $100 \mu \mathrm{g}$ per eye had significantly reduced lesion area (Fig. 9B).

\section{Discussion}

Current anti-VEGF therapies have had a dramatic impact on wet AMD treatment but require frequent intravitreal injections (4-6 weeks). In addition, only $30 \%-40 \%$ of patients with wet AMD are complete responders to anti-VEGF therapy, so a different mechanism of action may add increased efficacy to some patients (Chang et al., 2007; Bressler et al., 2009; Busbee et al., 2013; Heier et al., 2012). Thus, the unmet needs in the treatment of wet AMD are reduced dosing frequency and increased efficacy in incomplete responders. We sought a drug that would achieve a long duration of treatment of patients with wet AMD by inhibiting $\mathrm{PI} 3 \mathrm{~K} / \mathrm{mTOR}$ pathways.

At the onset of this program, we had ready access to many potent PI3K and PI3K/mTOR inhibitors (Folkes et al., 2008; Heffron et al., 2011; Ndubaku et al., 2013; Staben et al., 2010, 2011, 2013a,b; Sutherlin et al., 2010, 2011). Unique to this program for the treatment of retinal

TABLE 6

GNE-947 half-lives after a single IV or ITV injection in rabbits

\begin{tabular}{|c|c|c|c|c|}
\hline Route & Dose & Formulation & Matrix & Half-life (h) \\
\hline IV & $2.5 \mu \mathrm{g} / \mathrm{kg}$ & Solution & Plasma & 9.11 \\
\hline IV & $500 \mu \mathrm{g} / \mathrm{kg}$ & Solution & Plasma & 9.59 \\
\hline \multirow[t]{3}{*}{ ITV } & $2.5 \mu \mathrm{g}$ per eye & Solution & Plasma & 14.4 \\
\hline & & & Vitreous humor & 16.3 \\
\hline & & & Aqueous humor & 23.2 \\
\hline \multirow[t]{2}{*}{ ITV } & $33.5 \mu \mathrm{g}$ per eye & Suspension & Plasma & 705 \\
\hline & & & Eye & 1100 \\
\hline \multirow[t]{2}{*}{ ITV } & $100 \mu \mathrm{g}$ per eye & Suspension & Plasma & 1760 \\
\hline & & & Eye & 3440 \\
\hline \multirow[t]{2}{*}{ ITV } & $200 \mu \mathrm{g}$ per eye & Suspension & Plasma & 5250 \\
\hline & & & Eye & 4600 \\
\hline
\end{tabular}

IV, intravenous; ITV, intravitreal.
MALDI MS/MS Images:

Rabbit Left Eye 30d

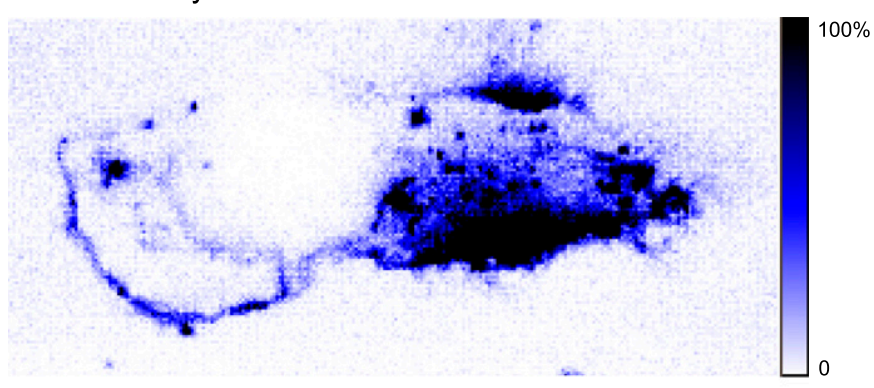

MALDI MS/MS Ion Image

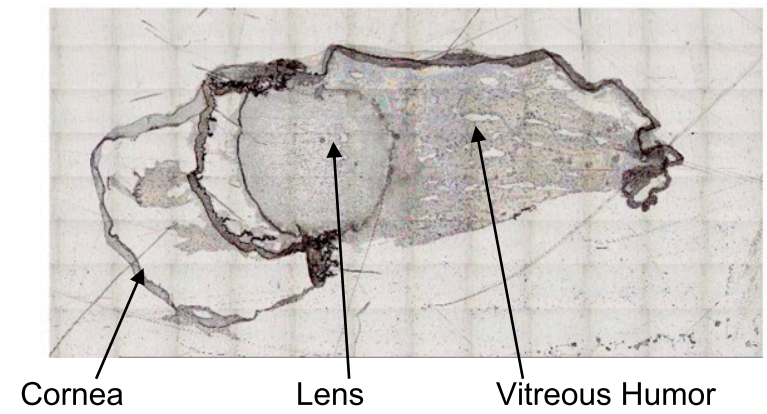

Optical Image

Fig. 6. Optical (A) and MALDI (B) images of a rabbit sagittal eye section after a single intravitreal dose of $1000 \mu \mathrm{g}$ per eye of GNE-947 on day 30

diseases, we wanted to ensure that the solubility was high enough to ensure the ability to sustain concentrations in the vitreous humor (to allow access to retina) 10 -fold over the cellular $\mathrm{EC}_{50}$. As we sought a long-lasting depot of drug in suspension, however, we also wanted the solubility of the molecules to be not too high to render short duration for the depot effects. For this reason, our target profile of PI3K/mTOR inhibitor was one that had a ratio of the solubility of the molecule to cellular $\mathrm{EC}_{50}$ that was in the 20- to 50-fold range. Although we had

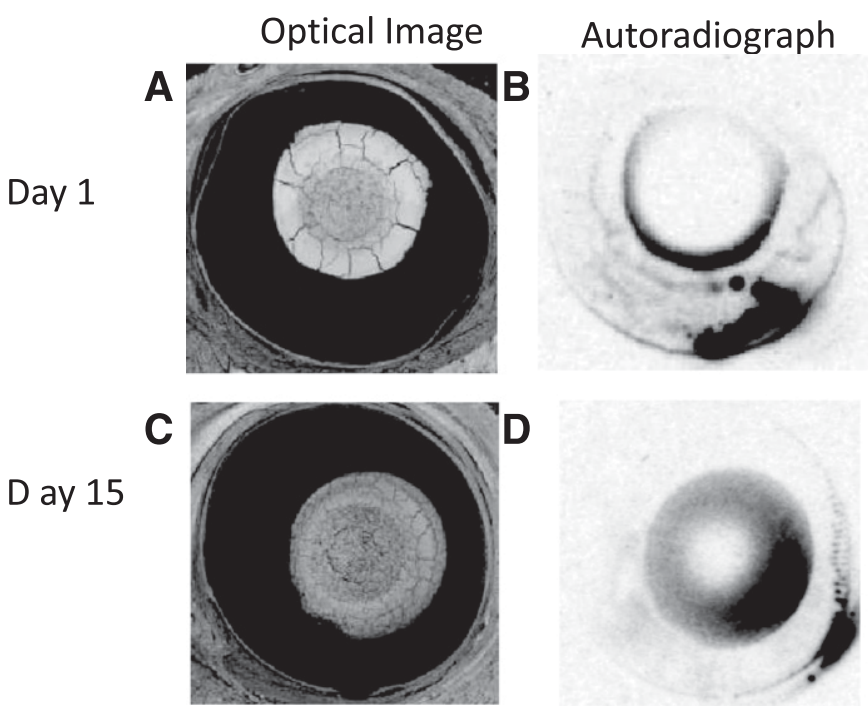

Fig. 7. Optical images and autoradiographs of rabbit frontal eye sections after a single intravitreal dose of $150 \mu \mathrm{g}$ per eye of GNE-947 on day 1 or day 15 . 

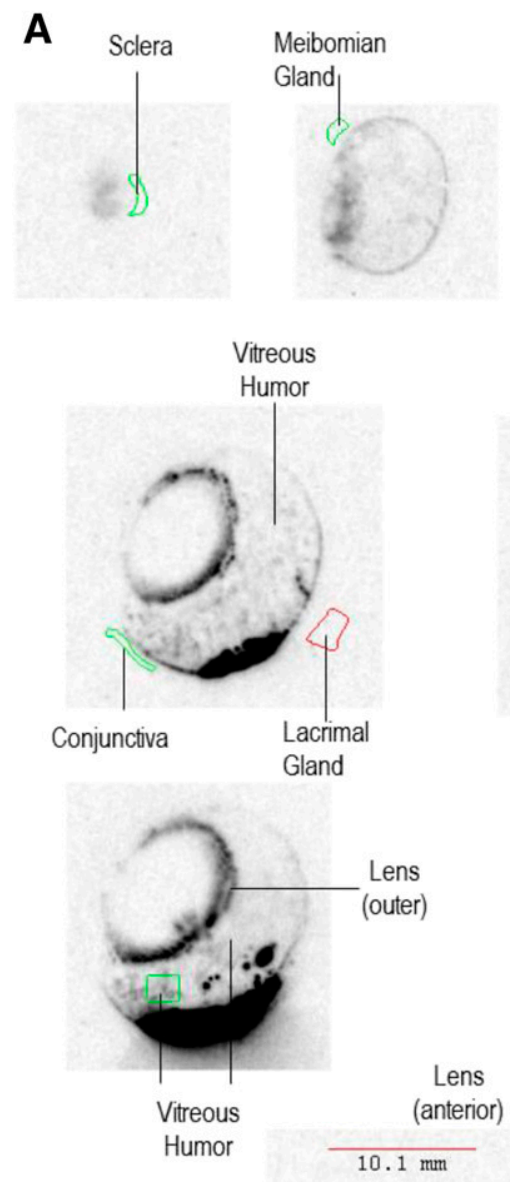
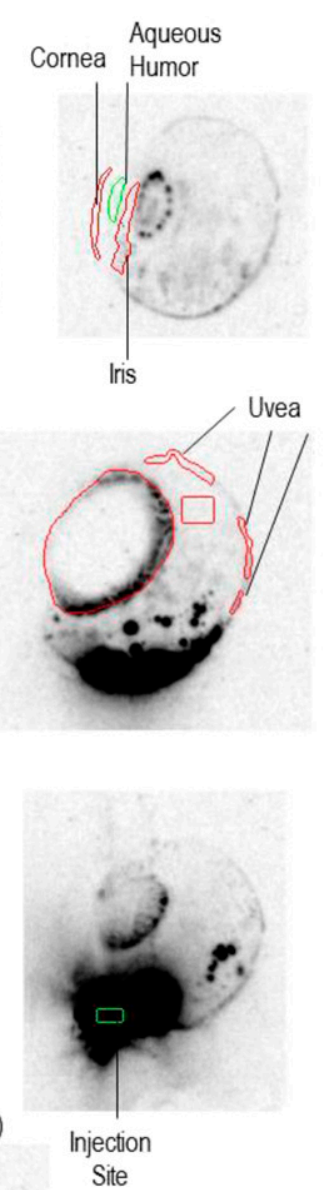

B
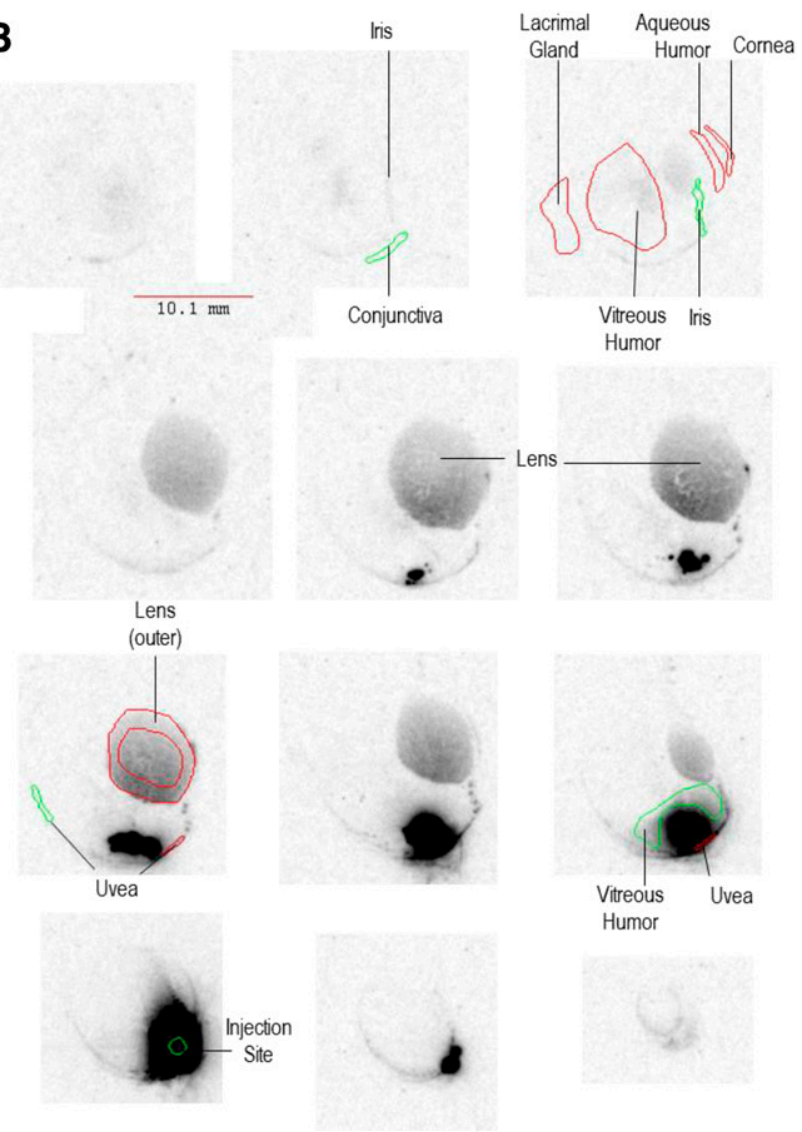

previously identified PI3K inhibitors that had advanced to clinical trials for cancer treatment, we deemed these molecules inadequate for this use because they had solubility/cell $\mathrm{EC}_{50}$ ratios that exceeded our target range (Supplemental Fig. 1). As our previous development candidates did not meet our target criteria with respect to solubility/cellular $\mathrm{EC}_{50}$, we selected 10 additional PI3K inhibitors to evaluate in an HUVEC migration assay and determined the kinetic solubility of these same molecules at $\mathrm{pH} 7.2$ (Table 1). These molecules were selected from multiple chemical scaffolds (Supplemental Fig. 2). GNE-947 met our criteria for further study, and additional data are presented in Supplemental Fig. 3.

In the present study, we showed that GNE-947 has a biphasic PK profile with a terminal $t_{1 / 2}$ of less than 1 day after a single intravitreal injection in a solution in rabbit eyes, which is slightly longer than the intravenous dose. Interestingly, it has a terminal $t_{1 / 2}$ of up to 6 months after a single intravitreal injection in a suspension at higher doses. These results support the feasibility to design a PI3K/mTOR inhibitor to treat wet AMD using intravitreal injection with dosing frequency of potentially once a year. The learning from GNE-947 ocular PK studies is helpful in designing drugs for the treatment of wet AMD and other posterior eye diseases that require a long duration of exposure.

Many ocular PK studies utilizing intravitreal administration are reported in the literature. However, few studies examined the drug concentrations in plasma, vitreous humor, and aqueous humor simultaneously, which is apparently because of a lack of sensitive bioanalytical methods to determine low drug concentration in the plasma (Urtti, 2006;
Del Amo and Urtti, 2015). In the present study, we developed a sensitive mass spectrometry method that was able to detect $5 \mathrm{pg} / \mathrm{ml}$ $(11 \mathrm{pM})$ as the lower limit of quantitation. This method allowed us to monitor the plasma concentrations after dosing as low as $2.5 \mu \mathrm{g}$ per eye in a solution formulation or monitor the plasma concentrations for several months after dosing of $200 \mu \mathrm{g}$ per eye in a suspension formulation. The extensive data generated in this study will be helpful to develop ocular physiologically based pharmacokinetic and ocular in silico $t_{1 / 2}$ prediction models to enable the design of drugs for the treatment of retinal diseases (Durairaj et al., 2009; Kidron et al., 2012; Del Amo and Urtti, 2015; del Amo et al., 2015; Vellonen et al., 2016).

After intravitreal injection of GNE-947 in solution formulation, the concentration-time profiles in vitreous humor, aqueous humor, and plasma were biphasic and parallel. A two-compartment model with a vitreous humor compartment and a hypothetical binding compartment were proposed based on the observed biphasic profiles and high binding affinity to melanin. The estimated terminal $t_{1 / 2}$ from the mean vitreous humor was 16.3 hours. This value is consistent with the range of reported intravitreal $t_{1 / 2}$ of 0.62-26.5 hours (del Amo et al., 2015). The estimated transfer clearance from vitreous humor to plasma $\left(\mathrm{Cl}_{\mathrm{vp}}\right)$ was $0.408 \mathrm{ml} / \mathrm{h}$ per eye. This value is consistent with the range of reported intravitreal clearance of $0.031-1.53 \mathrm{ml} / \mathrm{h}$ per eye (del Amo et al., 2015). The estimated volume for the vitreous compartment was $5.19 \mathrm{ml}$ per eye, which is outside the range of $0.72-3.14 \mathrm{ml}$ per eye reported in the literature for marketed drugs (del Amo et al., 2015). This may be due to higher lipophilicity of GNE-947 than marketed drugs studied in the literature. 

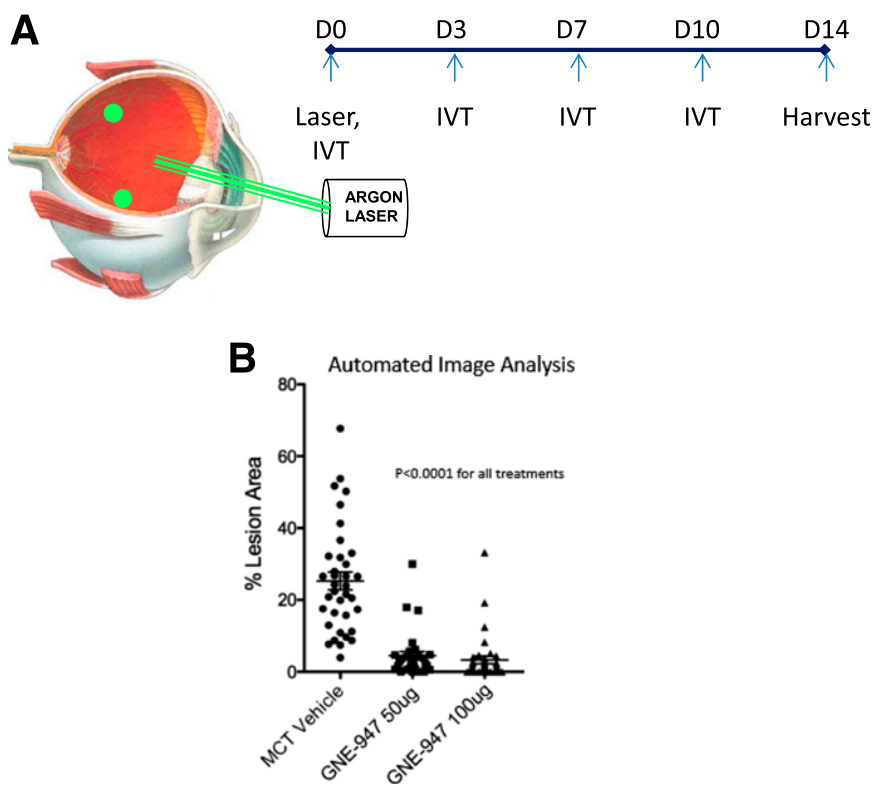

Fig. 9. Rat CNV efficacy study design and lesion location (A) and imaging analysis (B) after day 14 for animals dosed with GNE-947 at 50 or $100 \mu \mathrm{g}$ per eye. D, day; ITV, intravitreal; MCT, methylcellulose/tween.

There are two elimination routes from the eye for intravitreally injected drugs: anterior elimination of the drug through the aqueous humor flow and posterior elimination through blood-ocular barriers, such as iris epithelium, nonpigmented ciliary epithelium, and retinal capillaries (Ranta and Urtti, 2006; Urtti, 2006). Large, hydrophilic compounds with low membrane permeability, such as antibody drugs, are cleared from the vitreous humor via the anterior elimination route, and lipophilic low-molecular weight drugs with high permeability are cleared via the posterior elimination route. In the present study, the posterior elimination clearance is about 1000fold higher than the anterior elimination clearance, indicating that most of the GNE-947 was eliminated via a posterior route. This observation is consistent with the clearance mechanism for other low-molecular weight compounds reported in the literature (Del Amo and Urtti, 2015).

In suspension formulation, the plasma concentrations showed a biphasic curve with a similar maximal concentration at the three dose levels (Supplemental Fig. 4) but dose-proportional concentrations at later time points. We hypothesized that the $50-\mu 1$ suspension formulation of GNE-947 split into two pools after intravitreal injection. We propose that a fast-release pool, which was composed of solubilized drug and small-size particles similar at the three dose levels resulted in similar maximal concentration in the plasma regardless of dose levels as the injection volume was kept at $50 \mu \mathrm{l}$ for the three doses. We also propose that a slow-release pool compartment was composed of large particles, which required a longer time for distribution and/or elimination. The amount in the fast-release pool was estimated as $4.54 \mu \mathrm{g}$ per eye, which was estimated by fitting the model to the observed plasma concentrations and the amount in the eyes, which was only a small fraction of the administered dose (33.5-200 $\mu \mathrm{g}$ per eye).

In suspension formulation, there was a trend that the $t_{1 / 2}$ increased with increasing dose levels for both the plasma concentration and amount of drug in the eyes. In addition, using the model shown in Fig. 5A, using first-order transfer $\left(\mathrm{K}_{3}\right)$ from the slowrelease compartment to the fast-release compartment, described the observed plasma concentration well for the middle dose, but it slightly overpredicted the plasma concentrations for the high dose and slightly underpredicted it for the low dose (Supplemental Fig. 5). To explain the observed data, we assumed that the release rate from the slow-release pool to the fast-release pool was determined by the dissolution rate as expressed by the Noyes-Whitney equation or the Nernst and Brunner equation (Dokoumetzidis and Macheras, 2006):

$$
\text { dissolution rate }=A * D *\left(C_{s}-C_{b}\right) / d
$$

where A is surface area of the particles, D is diffusion coefficient, $\mathrm{C}_{\mathrm{s}}$ is solubility, $\mathrm{C}_{\mathrm{b}}$ is the concentration in the vitreous humor, and $\mathrm{d}$ is thickness of the boundary layer of the solvent at the surface of the dissolving substance.

If we assume the particles are spheres, the relationship between the surface area (A) and mass of the drug is (Kim et al., 2006)

$$
A=(6 \sqrt{\pi} \text { Mass } / \text { density })^{2 / 3} .
$$

From eqs. 14 and 15, we derived that dissolution rate is proportional to the Mass ${ }^{2 / 3}$ and used this relationship in eqs. 10 and 11 for the model in Fig. 5A. This model improved the prediction for the high dose and the low dose based on a visual inspection.

The results from our MALDI-IMS imaging and autoradioluminography studies were consistent with the assumption that dissolution was the rate-limiting step for the clearance of the drug in the vitreous humor. The MALDI-IMS image shows that most of GNE-947 was in the vitreous humor and was not homogeneously distributed on day 30 . The autoradioluminography studies clearly showed that drug in the vitreous humor remained as a single aggregate form, which resulted in reduced surface area exposed to the vitreous humor. This may have led to further decreasing its dissolution rate in addition to its low solubility.

In a CNV efficacy study (Fig. 9), a significant effect was demonstrated at both doses tested. For infrequent drug administration, we think there may be an optimal range for the solubility of a drug such that the solubility is low enough to allow long duration, but the rate of dissolution must be sufficiently high to maintain a sufficient concentration to inhibit its targets.

The plasma $t_{1 / 2}$ after an intravitreal injection is mainly determined by the slowest step of after kinetic processes: release of the drug from its formulation, ocular distribution, transfer from ocular tissue to systemic circulation, and finally systemic distribution and elimination. The plasma $t_{1 / 2}$ of $14.4-16.3$ hours after an intravitreal injection of a low-dose solution was slightly longer than 9.11-9.59 hours after an intravenous administration, indicating that ocular distribution and/or transfer from ocular tissue to systemic circulation is slightly slower than the systemic distribution and elimination for this drug. Interestingly, the observed plasma $t_{1 / 2}$ of 6 months after an intravitreal injection of a high-dose suspension was much longer than that of an intravitreal injection of a low-dose solution or an intravenous administration, indicating that the release of drug from its suspension formulation is the slowest step and determines the observed long plasma $t_{1 / 2}$. Our PK modeling, MALDI-IMS imaging, and autoradioluminography results consistently support this explanation.

In summary, the present work shows that GNE-947 is a potent $\mathrm{PI} 3 \mathrm{~K} / \mathrm{mTOR}$ inhibitor and exhibits anti-CNV activity in rat eyes. The duration of GNE-947 in the rabbit eyes after intravitreal injection in a solution is short, with a $t_{1 / 2}$ less than 1 day. However, the duration after intravitreal dose of a suspension is very long, with a $t_{1 / 2}$ up to 6 months due to its low solubility and slow dissolution process. These results indicate that intravitreal injection of a suspension formulation for low-solubility drugs can be used to achieve 
long-term drug exposure, which is potentially useful for the treatment of wet AMD and other retinal diseases.

\section{Acknowledgments}

The authors thank Jialin Mao and QPS for their assistance for the plasma protein binding and melanin binding study; Weilan Ye and Vladimir Bansteev for help in preparation of the manuscript; and Jason Ho, Cynthia Young, and Kirsten Messeck for conducting the in vivo study.

\section{Authorship Contributions}

Participated in research design: Liu, Liang, LeCouter, Wright, Lubach, Shahidi-Latham, Heffron, Hop.

Conducted experiments: Liang, LeCouter, Ubhayakar, Chen, Cheng, Lee, Lubach, Quiason, Solon.

Contributed new reagents or analytical tools: Heffron.

Performed data analysis: Liu, Chen.

Wrote or contributed to the writing of the manuscript: Liu, Liang, Heffron.

\section{References}

Bressler NM, Chang TS, Fine JT, Dolan CM, and Ward J; Anti-VEGF Antibody for the Treatment of Predominantly Classic Choroidal Neovascularization in Age-Related Macular Degeneration (ANCHOR) Research Group (2009) Improved vision-related function after ranibizumab vs photodynamic therapy: a randomized clinical trial. Arch Ophthalmol 127:13-21.

Busbee BG, Ho AC, Brown DM, Heier JS, Suñer IJ, Li Z, Rubio RG, and Lai P; HARBOR Study Group (2013) Twelve-month efficacy and safety of $0.5 \mathrm{mg}$ or $2.0 \mathrm{mg}$ ranibizumab in patients with subfoveal neovascular age-related macular degeneration. Ophthalmology 120: $1046-1056$

Caballero S, Swaney J, Moreno K, Afzal A, Kielczewski J, Stoller G, Cavalli A, Garland W, Hansen G, Sabbadini R, et al.(2009) Anti-sphingosine-1-phosphate monoclonal antibodies inhibit angiogenesis and sub-retinal fibrosis in a murine model of laser-induced choroidal neovascularization. Exp Eye Res 88:367-377.

Chang TS, Bressler NM, Fine JT, Dolan CM, Ward J, and Klesert TR; MARINA Study Group (2007) Improved vision-related function after ranibizumab treatment of neovascular agerelated macular degeneration: results of a randomized clinical trial. Arch Ophthalmol 125: $1460-1469$.

Del Amo EM and Urtti A(2015) Rabbit as an animal model for intravitreal pharmacokinetics: clinical predictability and quality of the published data. Exp Eye Res 137:111-124.

del Amo EM, Vellonen KS, Kidron H, and Urtti A(2015) Intravitreal clearance and volume of distribution of compounds in rabbits: in silico prediction and pharmacokinetic simulations for drug development. Euro J Pharm Biopharm 95 (Pt B):215-226.

Dokoumetzidis A and Macheras $\mathrm{P}(2006)$ A century of dissolution research: from Noyes and Whitney to the biopharmaceutics classification system. Int J Pharm 321:1-11.

Durairaj C, Shah JC, Senapati S, and Kompella UB(2009) Prediction of vitreal half-life based on drug physicochemical properties: quantitative structure-pharmacokinetic relationships (QSPKR). Pharm Res 26:1236-1260.

Ferrara N(1999) Molecular and biological properties of vascular endothelial growth factor. $J \mathrm{Mol}$ Med (Berl) 77:527-543.

Ferrara N, Gerber HP, and LeCouter J(2003) The biology of VEGF and its receptors. Nat Med 9 : 669-676.

Ferrara N, Damico L, Shams N, Lowman H, and Kim R(2006) Development of ranibizumab, an anti-vascular endothelial growth factor antigen binding fragment, as therapy for neovascular agerelated macular degeneration. Retina 26:859-870.

Folkes AJ, Ahmadi K, Alderton WK, Alix S, Baker SJ, Box G, Chuckowree IS, Clarke PA, Depledge P, Eccles SA, et al.(2008) The identification of 2-(1H-indazol-4-yl)-6-(4-methanesulfonyl-piperazin-1-ylmethyl)-4-morpholin-4-yl-thieno[3,2-d]pyrimidine (GDC-0941) as a potent, selective, orally bioavailable inhibitor of class I PI3 kinase for the treatment of cancer. J Med Chem 51:5522-5532.

Gerber HP, McMurtrey A, Kowalski J, Yan M, Keyt BA, Dixit V, and Ferrara N(1998) Vascular endothelial growth factor regulates endothelial cell survival through the phosphatidylinositol 3' kinase/Akt signal transduction pathway. Requirement for Flk-1/KDR activation. $J$ Biol Chem 273:30336-30343.

Graupera M, Guillermet-Guibert J, Foukas LC, Phng LK, Cain RJ, Salpekar A, Pearce W, Meek S, Millan J, Cutillas PR, et al.(2008) Angiogenesis selectively requires the p110alpha isoform of PI3K to control endothelial cell migration. Nature 453:662-666.

Hamada K, Sasaki T, Koni PA, Natsui M, Kishimoto H, Sasaki J, Yajima N, Horie Y, Hasegawa G, Naito M, et al.(2005) The PTEN/PI3K pathway governs normal vascular development and tumor angiogenesis. Genes Dev 19:2054-2065.

Heffron TP, Heald RA, Ndubaku C, Wei B, Augistin M, Do S, Edgar K, Eigenbrot C, Friedman L, Gancia E, et al.(2016) The rational design of selective benzoxazepin inhibitors of the $\alpha$-isoform of phosphoinositide 3-kinase culminating in the identification of $(S)$-2-((2-(1-Isopropyl-1H-1,2,4 triazol-5-yl)-5,6-dihydrobenzo[f]imidazo[1,2- $d][1,4]$ oxazepin-9-yl)oxy)propanamide (GDC-0326) J Med Chem 59:985-1002.

Heffron TP, Salphati L, Alicke B, Cheong J, Dotson J, Edgar K, Goldsmith R, Gould SE, Lee LB, Lesnick JD, et al.(2012) The design and identification of brain penetrant inhibitors of phosphoinositide 3-kinase $\alpha$. J Med Chem 55:8007-8020.

Heffron TP, Wei B, Olivero A, Staben ST, Tsui V, Do S, Dotson J, Folkes AJ, Goldsmith P, Goldsmith R, et al.(2011) Rational design of phosphoinositide 3-kinase $\alpha$ inhibitors that exhibit selectivity over the phosphoinositide 3-kinase $\beta$ isoform. J Med Chem 54: $7815-7833$

Heier JS, Brown DM, Chong V, Korobelnik JF, Kaiser PK, Nguyen QD, Kirchhof B, Ho A, Ogura Y, Yancopoulos GD, et al.; VIEW 1 and VIEW 2 Study Groups (2012) Intravitreal aflibercept (VEGF trap-eye) in wet age-related macular degeneration [published correction appears in Ophthalmology (2013) 120:209-210]. Ophthalmology 119:2537-2548.

Jo N, Mailhos C, Ju M, Cheung E, Bradley J, Nishijima K, Robinson GS, Adamis AP, and Shima DT(2006) Inhibition of platelet-derived growth factor B signaling enhances the efficacy of antivascular endothelial growth factor therapy in multiple models of ocular neovascularization. Am $J$ Pathol 168:2036-2053.

Kidron H, Del Amo EM, Vellonen KS, and Urtti A(2012) Prediction of the vitreal half-life of small molecular drug-like compounds. Pharm Res 29:3302-3311.

Kim H, Csaky KG, Chan CC, Bungay PM, Lutz RJ, Dedrick RL, Yuan P, Rosenberg J, GrilloLopez AJ, Wilson WH, et al.(2006) The pharmacokinetics of rituximab following an intravitreal injection. Exp Eye Res 82:760-766.

Koeberle MJ, Hughes PM, Skellern GG, and Wilson CG(2003) Binding of memantine to melanin: influence of type of melanin and characteristics. Pharm Res 20:1702-1709.

Lin B and Pease JH(2016) A high throughput solubility assay for drug discovery using microscale shake-flask and rapid UHPLC-UV-CLND quantification. J Pharm Biomed Anal 122:126-140.

Miller JW, Le Couter J, Strauss EC, and Ferrara N(2013) Vascular endothelial growth factor a in intraocular vascular disease. Ophthalmology 120:106-114.

Ndubaku CO, Heffron TP, Staben ST, Baumgardner M, Blaquiere N, Bradley E, Bull R, Do S, Dotson J, Dudley D, et al.(2013) Discovery of 2-\{3-[2-(1-Isopropyl-3-methyl-1H-1,2-4-triazol-5yl)-5,6-dihydrobenzo[f]imidazo[1,2- $d]$ [1,4] oxazepin-9-yl]-1 $H$-pyrazol-1-yl $\}$-2-methylpropanamide (GDC-0032): a $\beta$-sparing phosphoinositide 3-kinase inhibitor with high unbound exposure and robust in vivo antitumor activity. $J$ Med Chem 56:4597-4610.

O'Reilly KE, Rojo F, She QB, Solit D, Mills GB, Smith D, Lane H, Hofmann F, Hicklin DJ, Ludwig DL, et al.(2006) mTOR inhibition induces upstream receptor tyrosine kinase signaling and activates Akt. Cancer Res 66:1500-1508.

Ranta VP and Urtti A(2006) Transscleral drug delivery to the posterior eye: prospects of pharmacokinetic modeling. Adv Drug Deliv Rev 58:1164-1181.

Regillo CD, Brown DM, Abraham P, Yue H, Ianchulev T, Schneider S, and Shams N(2008) Randomized, double-masked, sham-controlled trial of ranibizumab for neovascular age-related macular degeneration: PIER Study year 1. Am J Ophthalmol 145: 239-248.

Sampath D, Oeh J, Wyatt SK, Cao TC, Koeppen H, Eastham-Anderson J, Robillard L, Ho CC, Ross J, Zhuang G, et al.(2013) Multimodal microvascular imaging reveals that selective inhibition of class I PI3K is sufficient to induce an antivascular response. Neoplasia 15 : 694-711

Schmidt-Erfurth U, Eldem B, Guymer R, Korobelnik JF, Schlingemann RO, Axer-Siegel R, Wiedemann P, Simader C, Gekkieva M, and Weichselberger A; EXCITE Study Group (2011) Efficacy and safety of monthly versus quarterly ranibizumab treatment in neovascular age-related macular degeneration: the EXCITE study. Ophthalmology 118: 831-839.

Schnell CR, Stauffer F, Allegrini PR, O'Reilly T, McSheehy PM, Dartois C, Stumm M, Cozens R, Littlewood-Evans A, García-Echeverría C, et al.(2008) Effects of the dual phosphatidylinositol 3-kinase/mammalian target of rapamycin inhibitor NVPBEZ235 on the tumor vasculature: implications for clinical imaging. Cancer Res 68 $6598-6607$.

Staben ST, Blaquiere N, Tsui V, Kolesnikov A, Do S, Bradley EK, Dotson J, Goldsmith R, Heffron TP, Lesnick J, et al.(2013b) Cis-amide isosteric replacement in thienobenzoxepin inhibitors of PI3-kinase. Bioorg Med Chem Lett 23:897-901.

Staben ST, Heffron TP, Sutherlin DP, Bhat SR, Castanedo GM, Chuckowree IS, Dotson J, Folkes AJ, Friedman LS, Lee L, et al.(2010) Structure-based optimization of pyrazolo-pyrimidine and -pyridine inhibitors of PI3-kinase. Bioorg Med Chem Lett 20:6048-6051

Staben ST, Ndubaku C, Blaquiere N, Belvin M, Bull RJ, Dudley D, Edgar K, Gray D, Heald R, Heffron TP, et al.(2013a) Discovery of thiazolobenzoxepin PI3-kinase inhibitors that spare the PI3-kinase $\beta$ isoform. Bioorg Med Chem Lett 23:2606-2613.

Staben ST, Siu M, Goldsmith R, Olivero AG, Do S, Burdick DJ, Heffron TP, Dotson J, Sutherlin DP, Zhu BY, et al.(2011) Structure-based design of thienobenzoxepin inhibitors of PI3-kinase. Bioorg Med Chem Lett 21:4054-4058.

Sutherlin DP, Bao L, Berry M, Castanedo G, Chuckowree I, Dotson J, Folks A, Friedman L, Goldsmith R, Gunzner J, et al.(2011) Discovery of a potent, selective, and orally available class I phosphatidylinositol 3-kinase (PI3K)/mammalian target of rapamycin (mTOR) kinase inhibitor (GDC-0980) for the treatment of cancer. J Med Chem 54:7579-7587.

Sutherlin DP, Sampath D, Berry M, Castanedo G, Chang Z, Chuckowree I, Dotson J, Folkes A, Friedman L, Goldsmith R, et al.(2010) Discovery of (thienopyrimidin-2-yl)aminopyrimidines as potent, selective, and orally available pan-PI3-kinase and dual pan-PI3-kinase/mTOR inhibitors for the treatment of cancer. J Med Chem 53:1086-1097.

Urtti A(2006) Challenges and obstacles of ocular pharmacokinetics and drug delivery. Adv Drug Deliv Rev 58:1131-1135.

Vellonen KS, Soini EM, Del Amo EM, and Urtti A(2016) Molecular Pharmaceutics, Prediction of ocular drug distribution from systemic blood circulation. Mol Pharm 13:2906-2911.

Wallin JJ, Guan J, Prior WW, Lee LB, Berry L, Belmont LD, Koeppen H, Belvin M, Friedman LS, and Sampath D(2012) GDC-0941, a novel class I selective PI3K inhibitor, enhances the efficacy of docetaxel in human breast cancer models by increasing cell death in vitro and in vivo. Clin Cancer Res 18:3901-3911.

Yuan TL, Choi HS, Matsui A, Benes C, Lifshits E, Luo J, Frangioni JV, and Cantley LC(2008) Class $1 \mathrm{~A}$ PI3K regulates vessel integrity during development and tumorigenesis. Proc Natl Acad Sci USA 105:9739-9744.

Address correspondence to: Dr. Timothy P. Heffron, Genentech, Inc., 1 DNA Way, South San Francisco, CA 94080. E-mail: heffron.timothy@gene.com 